\title{
Effects of local advection on the spatial sensible heat flux variation on a mountain glacier
}

\author{
Tobias Sauter $^{1,2}$ and Stephan Peter Galos ${ }^{2}$ \\ ${ }^{1}$ Climate System Research Group, Institute of Geography, Friedrich-Alexander University Erlangen-Nürnberg (FAU), \\ Erlangen, Germany \\ ${ }^{2}$ Institute of Atmospheric and Cryospheric Sciences, University of Innsbruck, Innsbruck, Austria \\ Correspondence to: Tobias Sauter (tobias.sauter@fau.de)
}

Received: 1 June 2016 - Published in The Cryosphere Discuss.: 15 June 2016

Revised: 26 September 2016 - Accepted: 25 October 2016 - Published: 24 November 2016

\begin{abstract}
Distributed mass balance models, which translate micrometeorological conditions into local melt rates, have proven deficient to reflect the energy flux variability on mountain glaciers. This deficiency is predominantly related to shortcomings in the representation of local processes in the forcing data. We found by means of idealized large-eddy simulations that heat advection, associated with local wind systems, causes small-scale sensible heat flux variations by up to $100 \mathrm{~W} \mathrm{~m}^{-2}$ during clear sky conditions. Here we show that process understanding at a few observation sites is insufficient to infer the wind and temperature distributions across the glacier. The glacier-wide hourly averaged sensible heat fluxes are both over- and underestimated by up to $16 \mathrm{~W} \mathrm{~m}^{-2}$ when using extrapolated temperature and wind fields. The sign and magnitude of the differences depend on the site selection, which is used for extrapolation as well as on the large-scale flow direction. Our results demonstrate how the shortcomings in the local sensible heat flux estimates are related to topographic effects and the insufficient characterization of the temperature advection process.
\end{abstract}

\section{Introduction}

The complex interaction of glaciers, atmosphere and topography constitutes a fundamental challenge in glaciological research. Countless studies aim to identify the climatic drivers behind observed glacier changes by using distributed mass and energy balance models (e.g., Arnold et al., 1996; Hock and Holmgren, 2005; Klok and Oerlemans, 2002; Mölg et al., 2009). While these kinds of models summarize our un- derstanding of the governing physical processes at a point scale, they have proven insufficient to reflect the variability of the energy and mass fluxes on mountain glaciers (e.g., Gurgiser et al., 2013; MacDougall and Flowers, 2011; Prinz et al., 2016). The reduced spatial and temporal variability predominantly results from shortcomings in the representation of local processes in the forcing data.

While large-scale weather shapes the environmental conditions in which mountain glaciers exist, the mass and energy exchange on individual glaciers is controlled by the micrometeorological conditions. Given the complex topography around mountain glaciers with its contrasting surface characteristics, it is not trivial to bridge the scale gap between the large-scale conditions and the local characteristics. The micrometeorological condition of the surface layer is directly influenced by the presence of the earth surface and quickly responds to changes in the surface energy budget. The radiative and turbulent heat fluxes cool and heat the near-surface air layer and determine the temperature distribution across the topography. Local temperature excess and deficit create buoyancy forces that drive the thermal wind systems, including the valley circulations, slope and glacier winds (e.g., Munro and Scott, 1989; Oerlemans and Grisogono, 2002; Sicart et al., 2014; Smeets et al., 2000; van den Broeke, 1997). The thermal wind phenomena are often superimposed and partly overwhelmed by the dynamically driven winds, which in turn are characterized by topographic effects. Heat advection associated with the mean flow and intermittent turbulent mixing events alter the thermal conditions and, finally, link it to the large-scale weather. 
The fluctuations of the thermal conditions are of practical interest for distributed glacier mass balance studies. For example, winds may advect warm air from the surroundings towards the glacier, which locally increase the downwarddirected sensible heat flux (Ayala et al., 2015; Shea and Moore, 2010; Hannah et al., 2000; Moore and Owens, 1984; Strasser et al., 2004). The energy surplus can be critical for the ablation, considering that the turbulent heat flux can represent $50 \%$ of the total energy during pronounced melt events on maritime midlatitude mountain glaciers in summer and even up to $30 \%$ on continental glaciers (e.g., Cullen and Conway, 2015; Gillett and Cullen, 2011; van den Broeke, 1997; Hock, 2005; Klok and Oerlemans, 2002; Oerlemans and Klok, 2002; Giessen et al., 2008; Moore and Owens, 1984). Therefore, a profound knowledge of the advection processes and the micrometeorological characteristics is required to accurately calculate melt rates and their variations in space and time.

A fundamental obstacle in studying small-scale boundary layer characteristics is that, even on well-studied mountain glaciers, the deficiency of monitoring activities restricts the process understanding, required for detailed research, to a few sites and limited time periods (e.g., Wagnon et al., 1999; Mölg and Hardy, 2004; Obleitner and Lehning, 2004; Reijmer and Hock, 2008; Nicholson et al., 2013). The phenomenological knowledge that is valid for the specific location and weather situation does not have greater significance beyond the case (e.g., Machguth et al., 2006; Gardner et al., 2013; Zemp et al., 2013). This constraint makes it challenging to infer on micrometeorological conditions from a limited number of observations. Glaciological modeling studies typically circumvent this obstacle by constructing meteorological forcing fields, e.g., for temperature and wind, from scattered observations using fixed or variable lapse rates (e.g., Greuell and Böhm, 1998; Carturan et al., 2015; Ayala et al., 2015; Petersen et al., 2013; Huintjes et al., 2015; Weidemann et al., 2013; Jarosch et al., 2012). The interpolated fields then serve for the estimation of turbulent fluxes at any given point on the glacier. As a result of the simplified assumptions, the modeled sensible heat flux distribution is unlikely to truly reflect the full variability in time and space. It is still an open scientific question how these assumptions impact the estimated local and glacier-wide melting rates (e.g., Immerzeel et al., 2014; Shaw et al., 2016). However, this question cannot be fully answered by means of a few individual observations.

To overcome this difficulty, we make use of high resolution large-eddy simulations (LES). The LES are considered as pseudo-reality - a testbed to identify the shortcomings in the local sensible heat flux estimates when the lack of observations restricts our micrometeorological knowledge to a few sites. The plausibility of the temperature interpolation algorithms and the derived sensible heat fluxes can be more strictly tested in a surrogate world of atmospheric simulations, which offer a realization of atmospheric states in which all target variables are known. The pseudo-reality at- mosphere is not required to be an observed real world case, but it does need to be a plausible realization of the atmosphere in the sense that relevant processes are realistically simulated. The advantage of such studies is that the surrogate atmosphere provides a perfect pseudo-observation of all the variables required to establish the skill of an interpolation method and hence the sensible heat flux calculations. While surrogate atmospheres have been widely used in downscaling studies, this approach is still novel in glaciological studies (e.g., Maraun, 2012; Vrac et al., 2007; Frías et al., 2006).

After a brief description of the LES model (Sect. 2), we show that the pseudo-reality realistically describes the relevant atmospheric processes observed in a glaciated mountainous region (Sect. 3). We begin by exploring the mean flow fields and turbulence characteristics and then address the spatial variations of the surface sensible heat flux. In Sect. 4, we use the bulk approach in concert with linearly interpolated fields based on virtual sites and analyze the impacts on the variability of the surface sensible heat flux. The last section provides a summary of the main findings.

\section{Methodology}

\subsection{Large-eddy simulation solver}

The pseudo-reality atmosphere is simulated by an OpenFOAM-based incompressible LES solver (Churchfield et al., 2014). The solver is based on the incompressible filtered Navier-Stokes equations, using the Boussinesq approximation for buoyancy, along with the following continuity equation:

$\frac{\partial \overline{\boldsymbol{U}}_{i}}{\partial \boldsymbol{x}_{i}}=0$.

The filtered momentum equation is given as

$$
\frac{\partial \overline{\boldsymbol{U}}_{j}}{\partial t}+\frac{\partial \overline{\boldsymbol{U}}_{i} \overline{\boldsymbol{U}}_{j}}{\partial \boldsymbol{x}_{i}}=-2 \epsilon_{i 3 k} \Omega \overline{\boldsymbol{U}}_{k}-\frac{\partial \bar{p}}{\partial \boldsymbol{x}_{j}}-\frac{\boldsymbol{\tau}_{i j}^{r}}{\partial \boldsymbol{x}_{i}}-\rho_{\mathrm{b}} \boldsymbol{g}_{j},
$$

with the overline denoting the LES filtering operation, $\overline{\boldsymbol{U}}_{i}$ the component of the resolved-scale velocity vector in the direction $\boldsymbol{x}_{i}, \epsilon_{i j k}$ the alternating unit tensor, $\Omega$ the planetary rotation rate vector, $\bar{p}$ the pressure, and $\boldsymbol{g}_{i}$ the gravitation vector. The strength and the sign of the buoyancy force $\rho_{\mathrm{b}}$ is given by

$\rho_{\mathrm{b}}=1-\left(\frac{\bar{\theta}-\theta_{0}}{\theta_{0}}\right)$,

where $\bar{\theta}$ is the resolved-scale potential temperature and $\theta_{0}$ is a reference temperature. In practise the isotropic part (residual kinetic energy, $\boldsymbol{k}_{r} \equiv 0.5 \boldsymbol{\tau}_{i j}^{R}$ ) of the residual-stress tensor $\boldsymbol{\tau}_{i j}^{R}=\overline{\boldsymbol{U}_{i} \boldsymbol{U}_{j}}-\overline{\boldsymbol{U}}_{i} \overline{\boldsymbol{U}}_{j}$ is absorbed into the filtered pressure 
term, and only the anisotropic residual-stress tensor,

$\boldsymbol{\tau}_{i j}{ }^{r} \equiv \boldsymbol{\tau}_{i j}{ }^{R}-\frac{2}{3} \boldsymbol{k}_{r} \delta_{i j}$,

needs to be modeled (also called subgrid-scale stress tensor). As in the vast majority of LES studies of stable boundary layers (SBL), we use a dynamic Smagorinsky subgrid-scale (SGS) model which relies on the eddy-viscosity assumption to solve Eq. (2). The model relates the residual stresses to the resolved large-scale velocity deformation

$\boldsymbol{\tau}_{i j}{ }^{r}=-2 v_{t} \overline{\boldsymbol{S}}_{i j}$

where $v_{t}$ is the eddy viscosity of the residual motions, and

$\overline{\boldsymbol{S}}_{i j}=\frac{1}{2}\left(\frac{\partial \overline{\boldsymbol{U}}_{i}}{\partial \boldsymbol{x}_{j}}+\frac{\partial \overline{\boldsymbol{U}}_{j}}{\partial \boldsymbol{x}_{i}}\right)$

is the resolved-scale strain rate tensor. The eddy viscosity

$v_{t}=\ell_{\mathrm{s}}^{2} \overline{\mathcal{S}}=\left(C_{\mathrm{s}} \bar{\Delta}\right)^{2} \overline{\mathcal{S}}$

is taken to be proportional to the Smagorinsky length scale, $\ell_{\mathrm{s}}$, and the characteristic filtered rate of strain $\overline{\mathcal{S}}=$ $\left(2 \bar{S}_{i j} \bar{S}_{i j}\right)^{1 / 2}$. The length scale is usually modeled by a fixed constant $C_{\mathrm{s}}$ and the filter width $\bar{\Delta}$. At high Reynolds number turbulence, with $\bar{\Delta}$ in the inertial subrange, the resolved scales account for nearly all of the kinetic energy (Pope, 2000). According to the model, the energy transfer from the resolved-scale eddies to the residual motions is entirely balanced by the dissipation of kinetic energy (Churchfield et al., 2014). While, in the mean, energy is transferred from the large to small scales, it has been recognized that locally there can be significant backscatter of energy from the residual motions on the resolved scales (Pope, 2000). Furthermore, Eq. (5) is only valid for isotropic turbulence and is therefore not strictly applicable to complex terrain. The importance of the effects of backscatter and anisotropy for SBL has been shown by Kosovic and Curry (2000). Nevertheless, we assume that the details of the model are of minor importance and the effect of anisotropy becomes negligible when the grid-scale is small compared to the energy-containing turbulent scales. Quantifying possible errors coming from this assumption or the model performance is challenging. The model can be tested either by a priori or a posteriori testing. The a priori test uses experimental or direct numerical simulation (DNS) data to relate directly the residual-stress tensor given by the closure model. In an a posteriori test the accuracy of calculated statistics, such as mean wind or momentum flux, is compared with experimental data. Most LES approaches use a posteriori test to prove its applicability. Churchfield et al. (2014) tested the Smagorinsky and bounded dynamic Lagrangian model with the GABLS intercomparison project (Global Energy and Water Cycle Experiment Atmospheric Boundary Layer Study; Beare et al., 2006) using a $6 \mathrm{~m}$ grid resolution. They found that both models are in line with the mean vertical profiles of wind speed, direction, potential temperature and variances. We therefore assume that the backscatter of energy from the SGS model towards the resolved scales is negligible when the LES resolves most of the turbulent kinetic energy (see Sect. 3.4).

In the original formulation the value of the constant $C_{\mathrm{s}}=$ 0.17 is derived from the Kolmogorov spectrum assuming that the transfer of energy to the residual motions is balanced by the dissipation. This constant, however, is not ideal for all locations of the flow (Churchfield et al., 2014), i.e., in regions where the buoyancy flux extinguishes the turbulence the residual shear stresses should be zero. In general, the value of $C_{\mathrm{s}}$ should become zero in the limit of laminar flow and any non-zero value of the coefficient would incorrectly lead to residual shear stresses. To overcome this issue Meneveau et al. (1996) proposed a Lagrangian averaged dynamic Smagorinsky model that allows the coefficient to vary in time and space based on the flow (Anderson and Meneveau, 1999; Sarghini et al., 1999; Bou-Zeid et al., 2005). This type of closure is appropriate for flow over complex terrain and is therefore used in this study (Bou-Zeid et al., 2005).

Proceeding from the instantaneous internal energy equation, the conservation of potential temperature can be derived and becomes

$\frac{\partial \bar{\theta}}{\partial t}+\frac{\partial \overline{\boldsymbol{U}}_{i} \bar{\theta}}{\partial \boldsymbol{x}_{i}}=-\frac{\boldsymbol{\tau}_{\theta i}}{\partial \boldsymbol{x}_{j}}$,

where $\boldsymbol{\tau}_{\theta i}$ is the SGS temperature flux given by

$\boldsymbol{\tau}_{\theta i}=-\frac{v_{t}}{P r_{\mathrm{t}}} \frac{\partial \bar{\theta}}{\partial x_{i}}$,

where $P r_{\mathrm{t}}$ is the turbulent Prandtl number. Changes in temperature by radiative forcing and phase change of water are neglected in this study.

The filtered momentum equation is solved using the PIMPLE algorithm and a preconditioned bi-conjugate gradient solver for asymmetric matrices. To reduce numerical dissipation the convective terms are solved using a second-order central differencing scheme with a multi-dimensional limiter. The time derivative is discretized by a second-order implicit scheme with adaptive time stepping.

\subsection{Study area}

Even though the LES is designed as pseudo-reality, the lower boundary condition is provided by a real topography. The designated study area is located at the head of Martell Valley in the central Ortles-Cevedale Group, Autonomous Province of Bozen, Northern Italy $\left(46.28^{\circ} \mathrm{N}, 10.60^{\circ} \mathrm{E}\right.$; see Fig. 1). The model domain comprises a major part of the contiguous glaciated area covering the northern section of the Cevedale Massif, the summit of which is the highest point of the study area (3769 $\mathrm{m}$ a.s.l.). Three glaciers connected to each other are the focus of the study: Fürkele Ferner, $\mathrm{Zu}$ fallferner and Langenferner. The surface area of the glaciers 


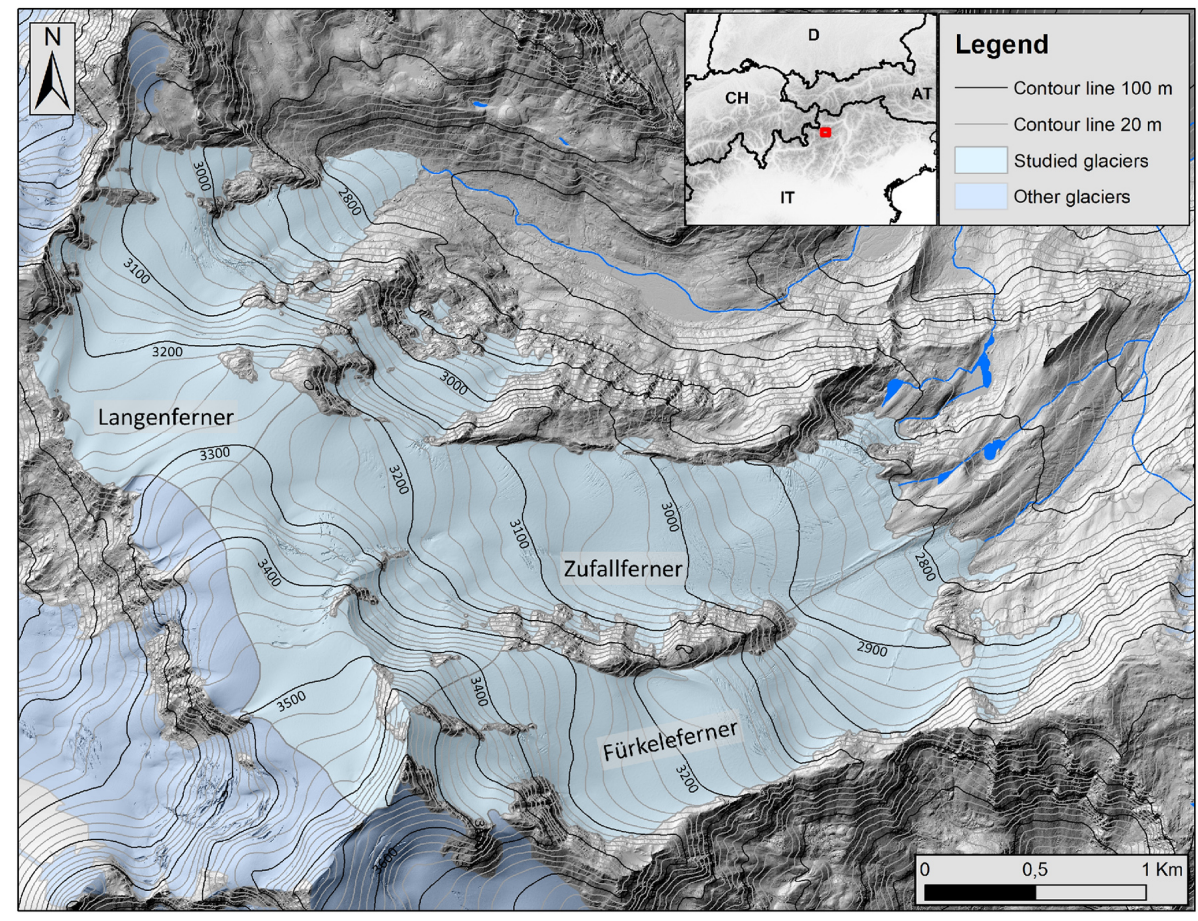

Figure 1. Map showing the surface topography of the studied glaciers and the surrounding terrain.

is about $6.62 \mathrm{~km}^{2}$ (2013) with an altitudinal extent from about $3750 \mathrm{~m}$ a.s.l near the summit of Hintere Zufallspitze, down to $2595 \mathrm{~m}$ a.s.l. at the lowest point of Zufallferner. The model domain includes a wide variety of topographic features such as steep slopes up to $50^{\circ}$ glaciated and unglaciated (summit) ridges of various aspects, as well as larger glacier sections with smooth terrain and low slope angles. The mean slope angle of the glacierized terrain is $17^{\circ}$. The topography can be regarded as (i) typical for many glaciers in the European Alps and (ii) highly suitable for investigating the complex interaction of large-scale (synoptic) forcing and smallscale topographic features.

\subsection{Initial conditions}

The surface temperature, $T_{\mathrm{S}}$, of both the glacier surface and the surrounding topography is uniformly initialized with $273.16 \mathrm{~K}$. The atmospheric background state for temperature and pressure is derived from ERA Interim reanalysis data from 17 August 2014, 06:00 UTC. The vertical data are uniformly mapped onto the unstructured LES grid. To avoid temperature jumps between the free atmosphere and the underlying surface an analytical Prandtl model for thermally induced slope flows is applied as proposed by Oerlemans and Grisogono (2002):

$\theta(z)=C e^{\frac{-z}{\lambda}} \cos \left(\frac{z}{\lambda}\right)$ where

$\lambda=\left(\frac{4 T_{0} K_{\mathrm{m}} K_{\mathrm{h}}}{\gamma g \sin ^{2}(\alpha)}\right)^{1 / 4}$

The pre-factor, $C$, is the temperature perturbation at the glacier surface, which in our case is the difference between surface temperature $(273.16 \mathrm{~K})$ and the ERA Interim temperature at $100 \mathrm{~m}$ above the surface. The quantity $\lambda$ is the natural length scale of the flow with $K_{\mathrm{m}}=K_{\mathrm{h}}=0.1 \mathrm{~m}^{2} \mathrm{~s}^{-1}$ the eddy diffusivity for momentum and heat, $\gamma$ the vertical temperature lapse rate, $\alpha$ the terrain slope, and $T_{0}=280 \mathrm{~K}$ the characteristic temperature. The temperature field in the lowest $50 \mathrm{~m}$ is further perturbed by random fluctuations of $0.1 \mathrm{~K}$. The wind field, $U$, is uniformly initialized with $8 \mathrm{~m} \mathrm{~s}^{-1}$ throughout the domain. This corresponds to the mean wind velocity of the ERA Interim data at $5500 \mathrm{~m}$.

\subsection{Boundary conditions}

The lateral boundaries are specified as periodic. At the top boundary a no-slip zero-stress boundary is used. The pressure gradient is set based on the Boussinesq density gradient normal to the boundary, and the potential temperature gradient is specified according to the initial profile. At the surface, the same pressure boundary condition is used as at the top boundary.

The filter and grid resolution are too coarse to resolve the near-wall motions, including in the viscous wall region, so that their influence close to the wall is modeled by a shear 
stress model. A local version of Schumann's shear stress model is applied at the surface (Churchfield et al., 2014; Schumann, 1975; Wan et al., 2007). The Reynolds stress tensor is zero except for the off-diagonal components $\boldsymbol{\tau}_{13}$ and $\tau_{23}$, with

$\boldsymbol{\tau}_{13}=-u_{*}^{2} \frac{\overline{\boldsymbol{U}_{x}}\left(z_{1}\right)}{\left|\overline{\boldsymbol{U}}\left(z_{1}\right)\right|}$,

$\boldsymbol{\tau}_{23}=-u_{*}^{2} \frac{\overline{\boldsymbol{U}_{y}}\left(z_{1}\right)}{\left|\overline{\boldsymbol{U}}\left(z_{1}\right)\right|}$,

where $u_{*}$ is the friction velocity, $z_{1}$ the height of the first cell center adjacent to the wall, and $\|$ denotes the magnitude of the local velocity parallel to the surface. To solve for the unknown friction velocity, the Monin-Obukhov scaling law is used. The details of the optimization are discussed by Churchfield et al. (2014). Strictly speaking, the MoninObukhov scaling law neither applies to complex terrain nor is it formulated to apply the laws locally (Stoll and PortéAgel, 2006; Wan et al., 2007). However, there is as yet no better solution to solve this problem.

The surface temperature flux is determined using MoninObukhov scaling laws for velocity and potential temperature (Basu et al., 2008). At each time step the surface temperature is updated according to the heating rate (see Sect. 2.5).

\subsection{Numerical experiments}

Given the large computational costs, the analysis is confined to four pseudo-realistic case experiments. The simulations merely differ in the geostrophic flow direction $(0,90,180$ and $270^{\circ}$ ). For the simulations, a constant pressure gradient is imposed to drive the geostrophic wind velocity of $8 \mathrm{~m} \mathrm{~s}^{-1}$ at a height of $5500 \mathrm{~m}$. The aerodynamic roughness height, $z_{0}$, is set to $0.1 \mathrm{~m}$ for the land surfaces (e.g., Stull, 2012) and to $0.001 \mathrm{~m}$ for the glacier and snow surface (e.g., Braithwaite, 1995; Giessen et al., 2008; Brock et al., 2000; Hock, 2005; Greuell and Smeets, 2001), respectively. We assume similar roughness height for snow and ice since large parts of the glaciers were covered by a thin layer of fresh snow. The glacier surface temperature is kept constant at the melting point during the simulation. The surrounding topography is heated with a constant heating rate of $1.2 \mathrm{Kh}^{-1}$. The atmospheric background state for temperature and pressure is derived from ERA Interim reanalysis data (Dee et al., 2011) from 17 August 2014 (see Sect. 2.3 for details). The selected day had clear skies apart from some isolated orographic clouds at the ridge south of Fürkele Ferner. The LES model is integrated for $8 \mathrm{~h}$. The mean quantities and statistics are calculated from the last simulation hour.

\subsection{Numerical mesh}

Besides the fluid dynamical challenges, the numerical model must be able to cope with complex topography. The OpenFOAM solver allows for unstructured grids, which can be adapted more easily to steep topography than commonly used terrain following grids. The 3-D unstructured mesh is generated with the OpenFOAM utility snappyhexmesh. The tool automatically generates hexahedra and split-hexahedra meshes from triangulated surface geometries, i.e., digital elevation models (DEMs). In this study, the mesh is generated from a high-resolution elevation model ( $1 \mathrm{~m}$ horizontal resolution) derived from airborne laser scans conducted in September 2013 (Galos et al., 2015). The horizontal extent of the computational domain is $10 \mathrm{~km} \times 10 \mathrm{~km}$ and is centered over the Zufallferner. The size should be sufficient to resolve the main scales that are involved in the turbulent energy generation. The domain top is set to $10 \mathrm{~km}$. In order to use periodic boundary conditions, opposite DEM boundaries are mirrored. This has been done by setting opposite grid points to their mean value and slowly relaxing (exponentially) the adjacent grid points in the inner domain using a spline algorithm (see Fig. 2). The resulting relaxation zone has a width of $2 \mathrm{~km}$ (160 grid points), which is sufficiently smooth to avoid numerical instabilities. Starting with an initial coarse hexahedra mesh, snappyhexmesh refines the cells close to the DEM surface by cell splitting and iteratively morphing the split-hex mesh to the surface. The initial isotropic background mesh has been set up with a grid spacing of $200 \mathrm{~m}$. In the lowest $300 \mathrm{~m}$ the final mesh has a horizontal resolution of $12.5 \mathrm{~m}$. From the meteorological point of view, the SBL with intermittent turbulence faces some challenges. According to the Monin-Obukhov similarity theory, the height above the ground $z$ and the Obukhov length $L_{\mathrm{S}}$ are the only relevant scaling variables (Stull, 2012). The theory is only valid within the surface layer, where the vertical divergence of the fluxes is negligible (variations smaller than $10 \%$ of their magnitude). However, the vertical gradient of the sensible heat flux above glaciers is normally greatest near the surface. Strictly speaking the Monin-Obukhov theory is not valid when the surface layer is below the observational or model level. This poses the need for a fine mesh close to the surface to allow adequate resolution of the smaller eddies. In order to better resolve the fluxes and shear stresses directly above the glacier the mesh has been further refined by prismatic inflation layers. The cell center of the first cell is located $0.6 \mathrm{~m}$ above the surface, and the heights of the adjacent cells increase with a constant expansion factor of 1.2. Altogether, the final prismatic layers have a total height of about $30 \mathrm{~m}$.

\subsection{Averaging and intermittency}

The LES resolves the large energy-containing turbulent structures, so that the output fields are fully turbulent. A given fully turbulent variable, $\widetilde{\phi}$, can be decomposed into the large-scale variation and the subgrid-scale turbulence as

$\widetilde{\phi}=\bar{\phi}+\phi^{\prime}$, 


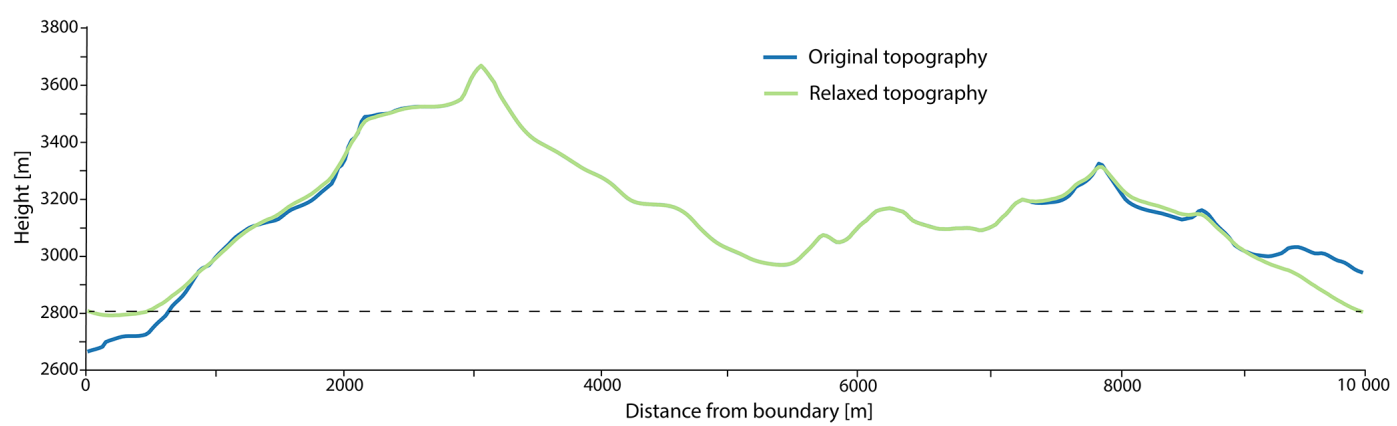

Figure 2. Adaption and relaxation of the computational domain. The blue and green lines show a east-west profile of the original and relaxed topography, respectively. The boundary grid cells have been set to the mean value of both cells (dashed line). The adjacent grid points are slowly relaxed (exponentially) to get a smooth transition from the boundaries towards the inner domain using a spline algorithm.

where the overbar is the grid cell average. The resolved turbulent contribution $\phi^{\prime \prime}$ is computed by

$\phi^{\prime \prime}=\bar{\phi}-\langle\bar{\phi}\rangle$,

where the operator \langle\rangle is the averaging timescale. In this study the timescale is chosen to be $1 \mathrm{~h}$ (Mahrt, 2010). The local values of the covariances are calculated as the average of the product of the fluctuations. Applying the Reynolds averaging rules finally leads to

$\left\langle\overline{\widetilde{w}^{\prime} \widetilde{\phi}^{\prime}}\right\rangle=\langle\bar{w}\rangle\langle\bar{\phi}\rangle+\left\langle\overline{w^{\prime \prime} \phi^{\prime \prime}}\right\rangle+\left\langle\overline{w^{\prime} \phi^{\prime}}\right\rangle$,

where the terms on the right-hand side represent the mean advective, resolved and subgrid-scale turbulent flux. As a general measure of turbulence strength we use the standard deviation of the vertical velocity:

$\sigma_{w}=\left(\left\langle\overline{w^{\prime} w^{\prime}}\right\rangle+\left\langle\overline{w^{\prime \prime} w^{\prime \prime}}\right\rangle\right)^{\frac{1}{2}}$.

Occasional bursting events tend to show a more pronounced tail, so that we use the skewness of the vertical velocity variance as a measure to characterize turbulent mixing events (Mahrt, 2010).

\section{The pseudo-reality atmosphere}

\subsection{Mean flow patterns and vertical profiles}

The following section analyses the mean modeled flow patterns and vertical profiles. The analysis is confined to the atmospheric boundary layer near the glacier surface and the kinematic flow properties affecting it. For the discussion we introduce four specific regions: (R1) ridge region, (R2) a steep ice fall, (R3) katabatic wind region, and (R4) divergence zone of katabatic wind. Local characteristics are discussed at four virtual sites on the glacier (Z1-4; see Fig. 3).

Figure 3 shows the mean wind velocity, $\langle\overline{\boldsymbol{U}}\rangle$, at $2 \mathrm{~m}$ above the ground for each of the four flow experiments. The flow accelerates as it passes over the summit ridges (R1) due to the strong pressure gradients between the windward side and the ridge region. After passing the ridge the higher pressure on the lee side slows down the flow again. The mean wind velocity at ridges, which are perpendicular to the synoptic flow, sometimes reaches more than $12 \mathrm{~m} \mathrm{~s}^{-1}$ even though the forcing wind velocity is only $8 \mathrm{~ms}^{-1}$ (Fig. 3a). The acceleration partly leads to a flow separation behind sharp ridges (grey dashed lines in Fig. 3), resulting in a thick trailing wake or bluff body formation. In these regions, strong shears generate turbulence, which is an important trigger for vertical mixing events.

On lower wider passes and gaps, the flow follows the topography and modifies the wind systems on the lee side. This is particularly evident at the long stretched glacier divide between Zufallferner and Fürkele Ferner (R1). The large-scale flow enhances the katabatic wind when both wind systems are aligned but retards it otherwise. Since the glaciers are west-east orientated, surface wind predominantly accelerates during westerly flow (see R2 in Fig. 3a). Generally, katabatic winds on the lee side of flat passes or glacier divides are strengthened by the synoptic flow.

In the central part of Zufallferner (R3), the wind velocities considerably vary with the large-scale flow directions. For example, northerly and easterly flows (Fig. 3b, c) significantly enhance the velocities at the southern boundary of $\mathrm{Zu}-$ fallferner. The local acceleration is the consequence of crossvalley circulation triggered by the surrounding topography. The strong positive sensible heat fluxes at the steep slopes create buoyancy forces that drive the thermal circulations. The associated low pressure at the foot of the slopes entrains air from above. While part of the entrained air merges with the upslope wind, the other part contributes to the glacier wind. The large-scale flow either suppresses or supports the upslope wind, and hence the entrainment. The results suggest that the intensity of the slope winds largely explains the wind variations on Zufallferner.

At the glacier tongue (R4), the large-scale flow hardly affects the surface winds. The katabatic winds gently drain down the glaciers (see Table 1) with velocities ranging be- 


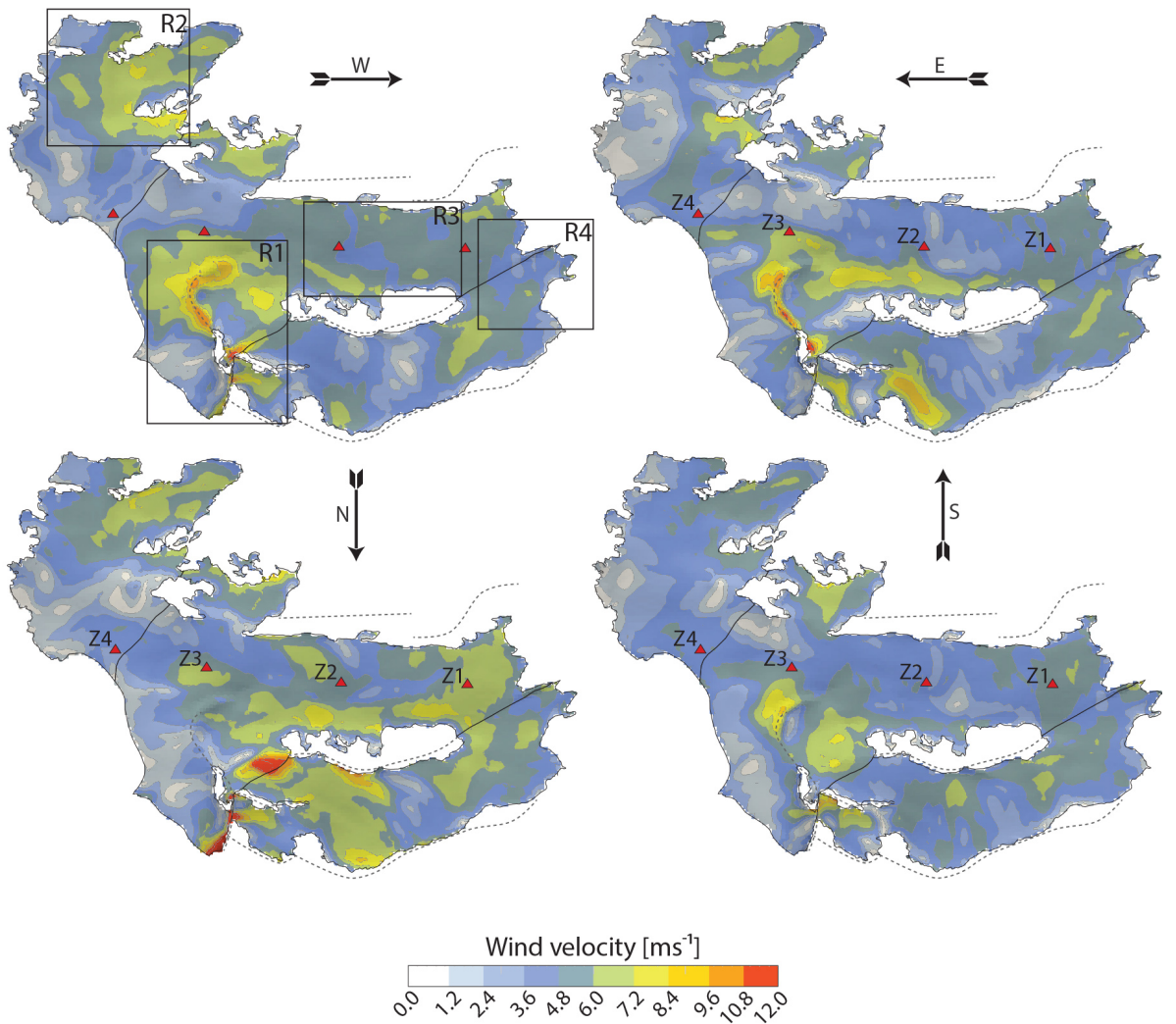

Figure 3. Mean velocity of the surface wind fields $(2 \mathrm{~m})$ for each of the four case experiment. The four boxes R1-4 and the sites Z1-4 define regions and locations on the glacier which are used for discussion in the results section. The grey dashed lines represent sharp ridges in the study area.

Table 1. Mean statistics at the sites (Z1-4) at $2 \mathrm{~m}$ above the surface, derived from the large-eddy simulations. Given are the heights of the LLJ (second column), wind velocities of the LLJ (third column), wind directions (fourth column), differences between the surface temperature and the temperatures at $100 \mathrm{~m}$ above the ground (fifth column), skewness of the vertical velocity variances (sixth column), integral turbulence scales (seventh to ninth column), and the bulk Richardson numbers (last column).

\begin{tabular}{lrrrrrrrrr}
\hline Experiment/location & $h(\mathrm{~m})$ & $v\left(\mathrm{~ms}^{-1}\right)$ & $\operatorname{dir}\left(^{\circ}\right)$ & $\theta_{\Delta}(\mathrm{K})$ & Skewness & $\frac{\sigma_{u}}{u_{*}}$ & $\frac{\sigma_{v}}{u_{*}}$ & $\frac{\sigma_{w}}{u_{*}}$ & $R i_{\mathrm{b}}$ \\
\hline West/Z1 & 3.3 & 5.0 & 235 & 13.3 & 2.35 & 4.96 & 4.54 & 0.96 & 0.04 \\
West/Z2 & 11.2 & 6.5 & 252 & 12.6 & 6.94 & 3.96 & 4.57 & 0.84 & 0.03 \\
West/Z3 & - & - & 203 & 10.8 & 3.14 & 3.41 & 2.70 & 0.54 & 0.02 \\
West/Z4 & - & - & 187 & 10.5 & 4.73 & 4.99 & 3.35 & 1.24 & 0.04 \\
\hline East/Z1 & 0.8 & 4.3 & 254 & 11.6 & 3.12 & 2.79 & 4.11 & 0.53 & 0.04 \\
East/Z2 & 11.2 & 5.0 & 266 & 11.0 & 2.26 & 3.40 & 6.05 & 0.64 & 0.03 \\
East/Z3 & 11.4 & 7.3 & 164 & 9.6 & 4.70 & 3.51 & 2.97 & 0.63 & 0.03 \\
East/Z4 & - & - & 234 & 9.2 & 3.33 & 3.89 & 4.67 & 1.26 & 0.03 \\
\hline North/Z1 & 11.3 & 9.1 & 240 & 13.1 & 3.11 & 4.26 & 6.99 & 0.91 & 0.03 \\
North/Z2 & 5.5 & 6.8 & 275 & 10.9 & 6.03 & 3.74 & 4.83 & 0.66 & 0.03 \\
North/Z3 & - & - & 225 & 9.8 & 6.05 & 3.14 & 2.43 & 0.47 & 0.02 \\
North/Z4 & - & - & 234 & 9.5 & 2.72 & 4.91 & 3.42 & 1.05 & 0.05 \\
\hline South/Z1 & 3.3 & 5.6 & 255 & 12.7 & 2.60 & 3.55 & 4.46 & 0.83 & 0.04 \\
South/Z2 & 5.5 & 5.5 & 290 & 11.2 & 2.90 & 4.13 & 4.41 & 0.77 & 0.03 \\
South/Z3 & 8.2 & 6.0 & 159 & 10.8 & 2.29 & 6.16 & 3.93 & 1.26 & 0.04 \\
South/Z4 & 1.5 & 5.1 & 163 & 10.0 & 2.09 & 4.63 & 5.27 & 1.32 & 0.05
\end{tabular}



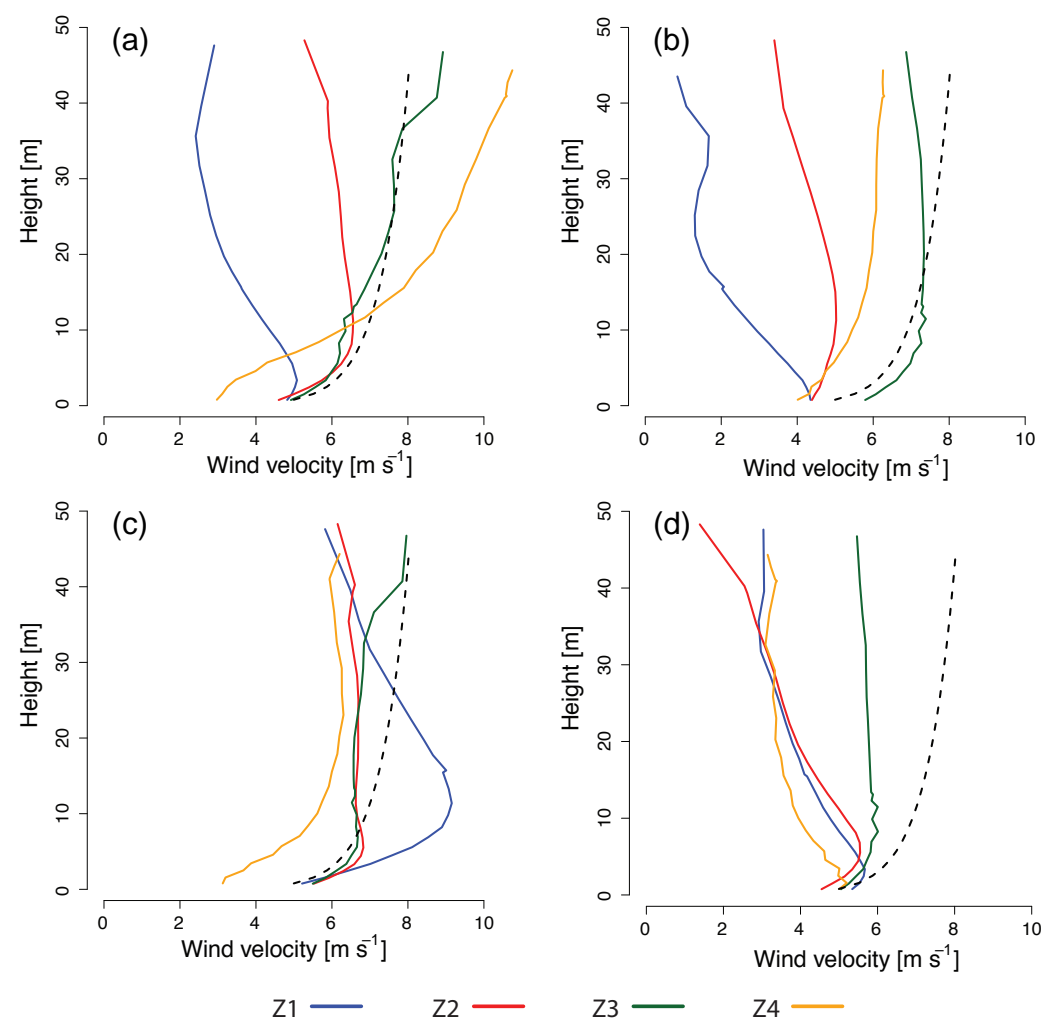

Figure 4. Vertical profiles of the mean wind velocity at the four sites (Z1, Z2, Z3 and Z4) for each case experiment. The dashed line represents a neutral logarithmic wind profile with $z_{0}=0.01 \mathrm{~m}$ and $u_{*}=0.3 \mathrm{~m} \mathrm{~s}^{-1}$.

tween 4.5 and $6.0 \mathrm{~m} \mathrm{~s}^{-1}$. Wind velocities are slightly higher for northerly flow $\left(\sim 7 \mathrm{~m} \mathrm{~s}^{-1}\right)$. The wind magnitudes are characteristic for mountain glaciers during clear sky conditions (e.g., van den Broeke, 1997; Söderberg and Parmhed, 2006). At $Z 1$ and $Z 2$ the low level jet (LLJ) is consistently found below the lowest $12 \mathrm{~m}$ (see Fig. 4). However, the intensity and height of the LLJ vary from case to case. The previously discussed crosswind circulation and its associated enhanced mass flux during northerly flow significantly lift and intensify the LLJ (see Table 1). Strong valley winds, however, tend to retard the down-slope winds by friction which weakens and lowers the LLJ (e.g., at site Z1, see Fig. 4b). Similarly, a reduced fetch and, in particular, a strong shear associated with a rapid veering of the winds with height can drastically reduce the wind velocity. Such a situation appears within the surroundings of $\mathrm{Z} 4$ when the down-slope flows are superimposed by southerly large-scale flow (see Fig. 4d).

The temperature deficit increases towards the glacier tongue (from $\mathrm{Z4}$ to $\mathrm{Z1}$ ) and implies a larger forcing to the glacier wind (see Table 1 and Fig. 5). However, the reverse situation is observed, as illustrated in Fig. 4. The intensity and height of the wind maximum decreases down-slope for most cases (see Fig. 4a, b, d), which somehow contradicts the often observed structure of katabatic flows. The reason for this is the still perceptible influence of the large-scale flow on the katabatic winds down to site Z2. This is evidenced by

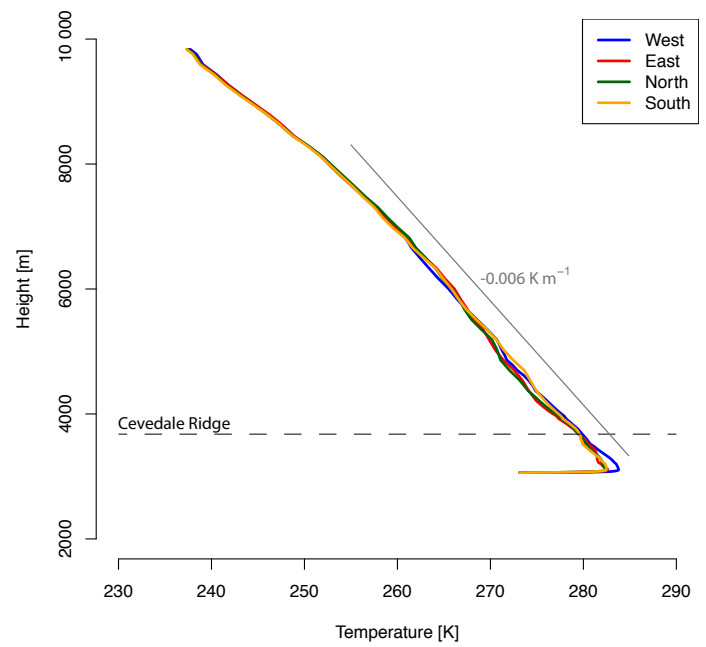

Figure 5. Vertical temperature profiles at location $\mathrm{Z} 2$ for each experiment. The dashed line indicates the altitude of the Cevedale ridge. The grey solid line represents a lapse rate of $-0.006 \mathrm{~K} \mathrm{~m}^{-2}$.

the fact that no wind maximum is found at the higher sites, Z3 and Z4. Nevertheless, there is a significant positive correlation (0.66) between the height and strength of the LLJ. 

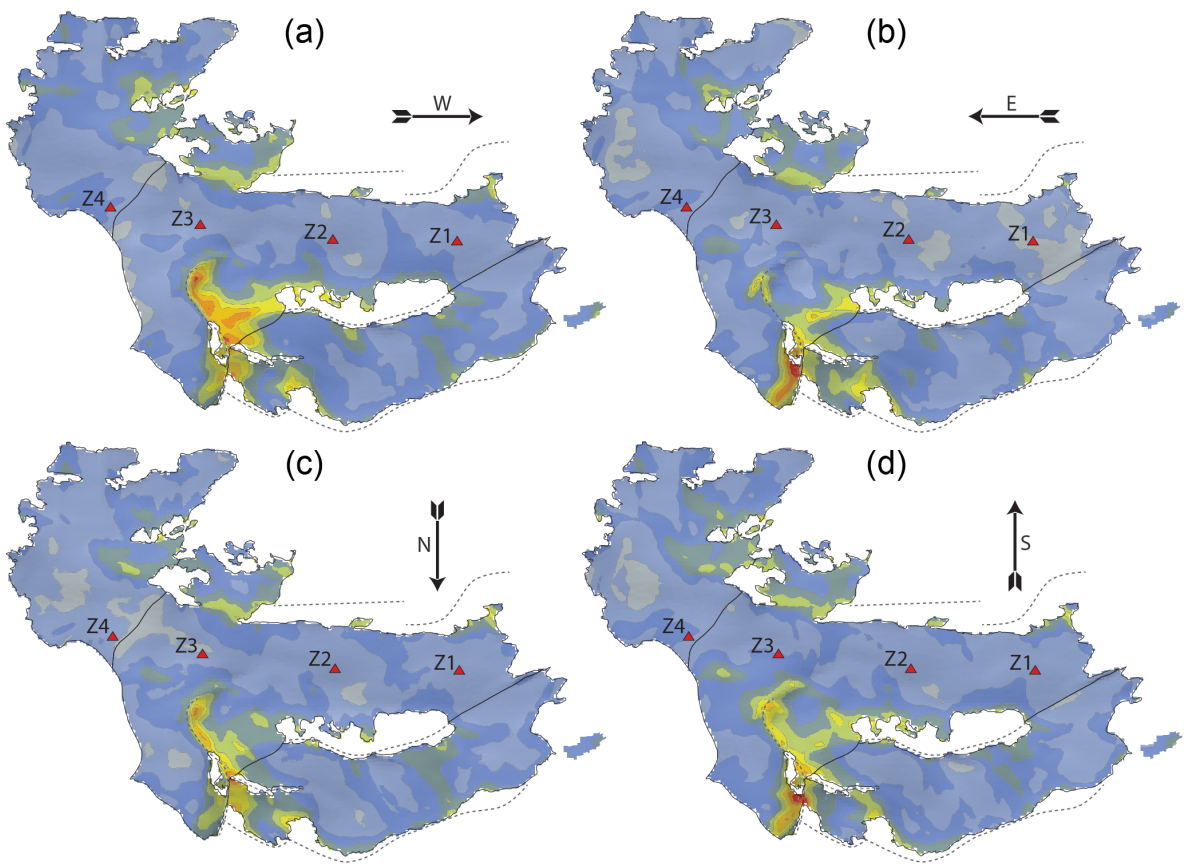

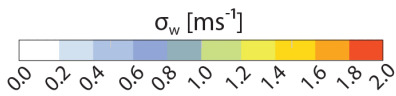

Figure 6. Standard deviation of the vertical velocity fluctuation at $2 \mathrm{~m}$ above ground for each of the four case experiments.
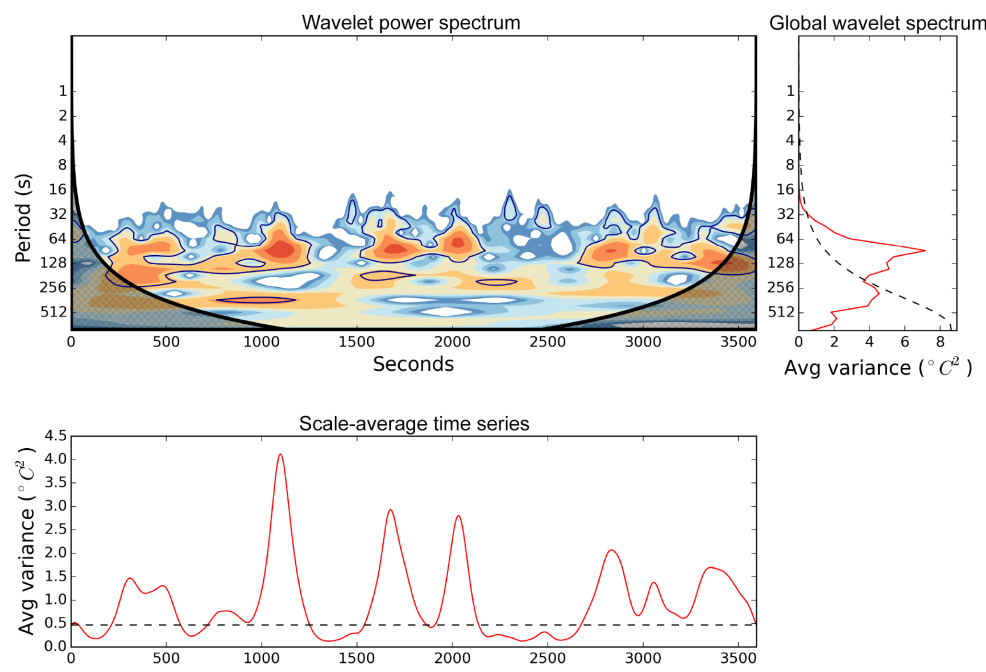

Figure 7. Example of a rectified wavelet power spectrum of the temperature signal at location $\mathrm{Z} 2$ for southerly flow (upper left column), the time average-wavelet power spectra (right column), and the scale-averaged time series (lower left column). Red and blue indicate high and low scaled powers (in base 2 logarithm), respectively. Black lines outline the wavelet spectrum at a $95 \%$ confidence level. The cross-hatched region marks the cone of influence, where edge effects become important. 

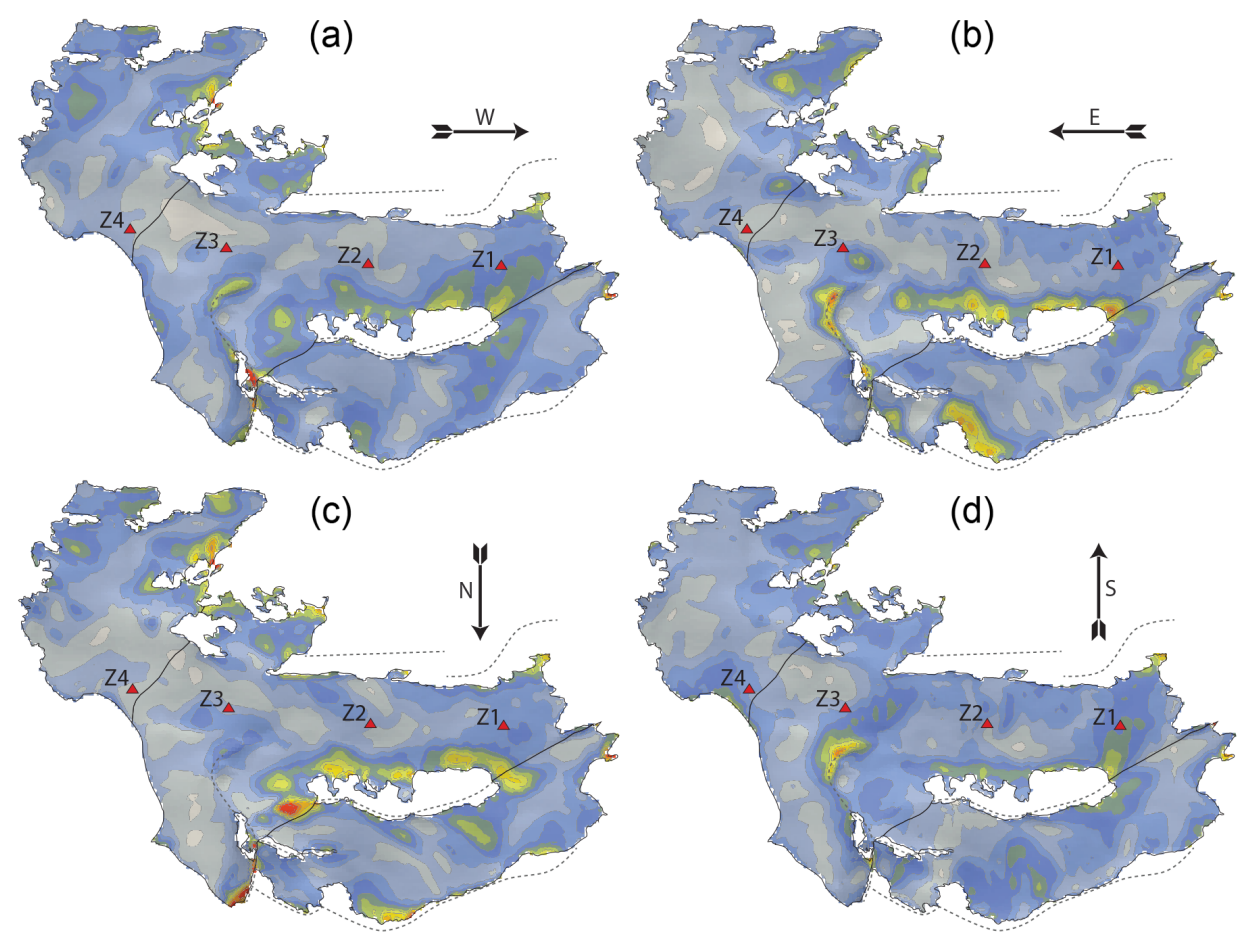

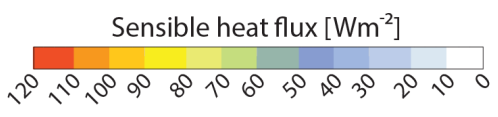

Figure 8. Mean sensible heat flux from the LES runs for each of the four case experiments.

\subsection{Turbulence characteristics and intermittency}

Figure 6 shows the standard deviation of the vertical velocity fluctuations, $\sigma_{w}$, at $2 \mathrm{~m}$ above the ground. Along the ridges turbulence is produced by shears and advected downwind with the flow. Therefore highest values of up to $2.0 \mathrm{~m} \mathrm{~s}^{-1}$ do not appear in areas with high wind velocities but are rather being found behind the sharp ridges.

At some distance away from the mountain ridges the boundary layer is less turbulent $\left(\sigma_{w}<0.5 \mathrm{~m} \mathrm{~s}^{-1}\right)$. However, the distributions of $\sigma_{w}$ at the sites $\mathrm{Z} 1-4$ are heavily rightskewed (see Table 1), which is a good indication of occasional mixing events embedded within the turbulence. Several studies observed intermittent turbulent mixing events in the SBL above glaciers and analyzed their impact on the surface energy balance (e.g., Cullen et al., 2007; Oerlemans and Grisogono, 2002; Söderberg and Parmhed, 2006; van den Broeke, 1997; Smeets et al., 1998; Munro and Davies, 1978; Hoinkes, 1954; Kuhn, 1978; Munro and Scott, 1989). Single mixing events may have only little impact on the timeaveraged quantities, but the intermittent heat supply can be substantial for the melt energy (Oerlemans and Grisogono, 2002; Dadic et al., 2013; Mahrt, 2010; van den Broeke, 1997). Local turbulent mixing events are driven by the characteristics of local turbulence, submeso motions, and the large-scale flow (Helgason and Pomeroy, 2012; Poulos et al., 2007; Högström et al., 2002). Non-local topographic effects, such as gap flows or bluff bodies, can favor the probability of periodic occurrence of burst events at a given point on the glacier, shaping the local micrometeorological conditions (Söderberg and Parmhed, 2006; Litt et al., 2015).

The vertical mixing of momentum and heat is a nonstationary process with changing frequency and intensity across time (Torrence and Compo, 1998; Roesch and Schmidbauer, 2014). Therefore, it is convenient to analyze the frequency structure of recurrent intermittency by decomposing the temperature signal into time-frequency space using wavelets. To illustrate the characteristics of intermittency we have calculated the wavelet power spectrum of the temperature signal at Z2 (southerly flow). Figure 7 shows the normalized wavelet spectrum and the average power taken over time. The global spectrum shows that most of the power is concentrated around $90 \mathrm{~s}$. There are variations in the frequency of occurrence and amplitude of the mixing events. On average episodic mixing events occur every $10 \mathrm{~min}$ and last for about $90 \mathrm{~s}$. The wavelet spectrum differs at each site and flow (not shown), but characteristic events are present in all cases. The frequency structure of the recurrent mixing events implies that the surface layer is episodically affected by anisotropic large-scale eddies. Contrary to near- 
neutral conditions, integral turbulence scales differ significantly between the horizontal and vertical components (see Table 1). The scales are on the same order of magnitude as those found by other studies (e.g., Litt et al., 2015; Söderberg and Parmhed, 2006). Since the stable stratification is weak in the surface layer $\left(R i_{\mathrm{b}} \sim 0.04\right)$, it is very unlikely that the downward-directed sensible heat flux is strong enough to explain these large differences. More importantly, the distortion of the detached eddies (turbulence) in the surface layer by local shear leads to groups of elongated sloping eddies (Högström et al., 2002).

\subsection{Spatial variations of the surface sensible heat flux}

According to the principle of energy conservation the local change in the potential temperature tendency of dry air at any given point is related to the advective, turbulent and the radiative heat fluxes. The latter one is not explicitly modeled in this study but indirectly given by the prescribed surface temperature. In this case, the heating and cooling of the nearsurface layer is only a result of the advective and turbulent transport. Local advection is usually negligible over flat terrain and during weak wind conditions, but it is considered a relevant process on mountain glaciers with consequences on the spatial variations of the surface heat flux (Moore and Owens, 1984).

Figure 8 shows the spatial variability of the modeled mean sensible heat flux on the glaciers. The fluxes vary locally between 10 and $120 \mathrm{~W} \mathrm{~m}^{-2}$, with slightly smaller values in the higher parts of the glacier due to lower temperatures. Note that positive signs indicate downward-directed fluxes. Along the glacier centerlines the sensible heat fluxes are in the range of 20 to $60 \mathrm{~W} \mathrm{~m}^{-2}$, which is in good accordance with observations made on midlatitude glaciers during clear sky conditions (e.g., Giessen et al., 2008; Oerlemans and Klok, 2002; Greuell and Smeets, 2001; Brock et al., 2000). Enhanced sensible heat fluxes occur in the peripheral zones of glaciers and along narrow and deeply carved valleys (e.g., Langenferner, R2), where strong cross-valley circulations locally advect air towards the glacier (see Fig. 9). The glacier topography locally inhibits a far-reaching advection and restricts the zone of influence to a narrow band along the glacier margin (e.g., R3). Accordingly, the peripheral glacier zones show the highest variability.

Between the individual experiments the spatial variability shows striking differences (see Fig. 8). However, these differences are small or even negligible when taking the glacierwide averages (see Table 2). These findings have important implications on glacier mass balance studies. On the one hand, distributed mass balance estimates (models) require a fundamental understanding of the heat advection (Fig. 9), since the sensible heat flux can make over $30 \%$ of the total energy during large melt events on continental midlatitude mountain glaciers in summer (e.g., van den Broeke, 1997; Hock, 2005; Klok and Oerlemans, 2002; Oerlemans and Klok, 2002; Giessen et al., 2008; Moore and Owens, 1984). On the other hand, we can conclude that topographic effects are less crucial for mean glacier-wide mass change estimates, although of course the calculated amount of total ablation can depend on the spatial (altitudinal) distribution of the sensible heat flux since additional energy causes more melt in areas where the surface temperature is at the melting point. In areas with surface temperatures lower than the melting point more energy is consumed by the ground heat flux to warm up the glacier.

While advection is essential for local estimates the question remains whether the impact of recurrent mixing events is of the same order of magnitude (see Sect. 3.2). Although the intermittent events temporarily increase the temperature in the surface layer and the sensible heat flux (see Fig. 7), there is little evidence that these events impact the mean potential temperature (see Fig. 9) and the time-averaged fluxes (see Fig. 8). In conclusion, local thermal micrometeorological conditions are mainly shaped by warm air advection through the cross-valley circulations.

\subsection{Reliability of the LES experiments}

Even though the pseudo-reality atmosphere seems to describe realistically the physical processes and patterns, the simulations must be interpreted with care. The patterns depend on the model assumptions, which include parameterizations and idealized boundary conditions.

A crucial assumption is the surface roughness length. To obtain more general results, uniform values of $z_{0}$ for snow and ice with $0.001 \mathrm{~m}$ are used, which is in the range of commonly used values (e.g., Brock et al., 2006, 2000; Braithwaite, 1995; Giessen et al., 2008; Hock, 2005; Greuell and Smeets, 2001). The "uniform" assumption ignores temporal and spatial roughness length variations. However, potentially such variations can have a strong influence on the magnitude of the surface energy fluxes (Brock et al., 2000; Giessen et al., 2008). We argue that this assumption is acceptable since large parts of the glaciers were covered by a thin layer of fresh snow.

The roughness lengths of snow and ice are relatively small compared to non-uniform roughness elements at a scale of tens of meters such as deep seracs or ice falls. The scales of these elements are approximately of the same order as the horizontal model resolution. Enhanced mixing due to the sudden roughness changes are therefore not resolved by the model, and it is very likely that the model underestimates the overall variability.

In general, the model resolution is very decisive for the overall quality of the LES simulations. LES require that $\sim 80 \%$ of the turbulent kinetic energy is resolved by the model itself, and only a minor part is modeled by the SGS model (Pope, 2000). In the performed experiments, on average $20-30 \%$ of the total turbulent kinetic energy is modeled by the SGS model. Slightly higher fractions, of up to $40 \%$, 

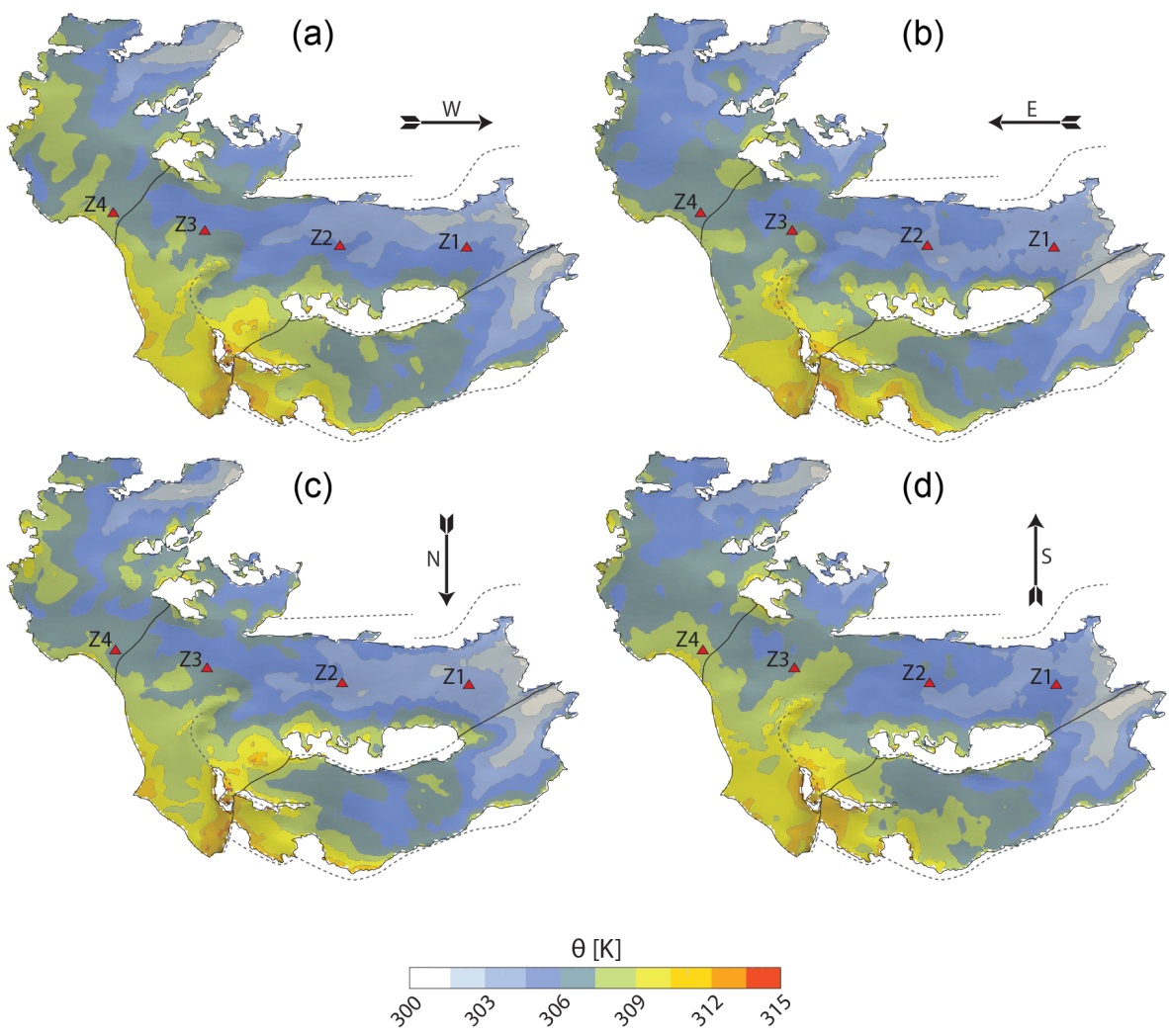

Figure 9. Potential temperature at $2 \mathrm{~m}$ above the surface for each of the four case experiment. The sites $\mathrm{Z} 1-4$ define regions and locations on the glacier which are used for discussion in the results section. The grey dashed lines represent sharp ridges in the study area.

Table 2. Comparison of the surface heat fluxes. Shown are the glacier-wide averaged surface heat fluxes from the LES and the estimated fluxes calculated with the bulk approach using different temperature fields as predictor (linearly interpolated and a thermodynamic glacier wind model based on Greuell and Böhm, 1998). The mean relative differences are given in the brackets.

\begin{tabular}{lrrrr}
\hline & West & East & North & South \\
\hline Large-eddy simulation $\left(\mathrm{W} \mathrm{m}^{-2}\right)$ & 33.8 & 31.2 & 33.8 & 33.0 \\
Linear interpolation $\left(\mathrm{W} \mathrm{m}^{-2}\right)$ & $26.9(-20.3)$ & $26.0(-16.6)$ & $27.4(-19.3)$ & $33.8(+2.2)$ \\
Greuell and Böhm $(1998)\left(\mathrm{W} \mathrm{m}^{-2}\right)$ & $35.5(+5.0)$ & $26.4(-16.4)$ & $31.5(-6.8)$ & $28.8(-12.7)$ \\
\hline
\end{tabular}

are found at exposed mountain ridges. When decreasing the horizontal grid resolution to $25 \mathrm{~m}$, the resolved kinetic energy was only $60-70 \%$. Additionally, a coarser grid leads to greater aspect ratios of the prismatic layers, which requires very short integration time steps $(0.01 \mathrm{~s})$ to guarantee stability. Increasing the prismatic layer heights is problematic since this affects the shear stress and momentum calculations close to the surface. The choice of $\sim 12.5 \mathrm{~m}$ is a good tradeoff between computational costs and resolved scales.

The Lagrangian averaged dynamic Smagorinsky model assumes that the energy transfer from the resolved-scale eddies to the residual motions is entirely balanced by the dissipation of kinetic energy. However, dissipation is not necessarily in balance with the energy production in stably stratified boundary layers. As a consequence, the SGS model is likely to dissipate too much energy. We have shown that the calculated statistics, such as the integral turbulence scales, skewness and vertical velocity variance, are in the same order of magnitude as those obtained from observations (e.g., Litt et al., 2015; Söderberg and Parmhed, 2006). If the SGS model is too dissipative, the calculated measures would be significantly lower than the observations. Which SGS model works best for stable boundary layers is not easy to tell, but the Lagrangian averaged SGS model seems to work well in our study. We have also tested the dynamic Smagorinsky model, but the simulations are found to be unstable due to large fluctuations of $C_{\mathrm{s}}$.

We like to note that the current version of the solver ignores differential surface heating by radiation and is therefore only suitable for idealized simulations. Differences in 

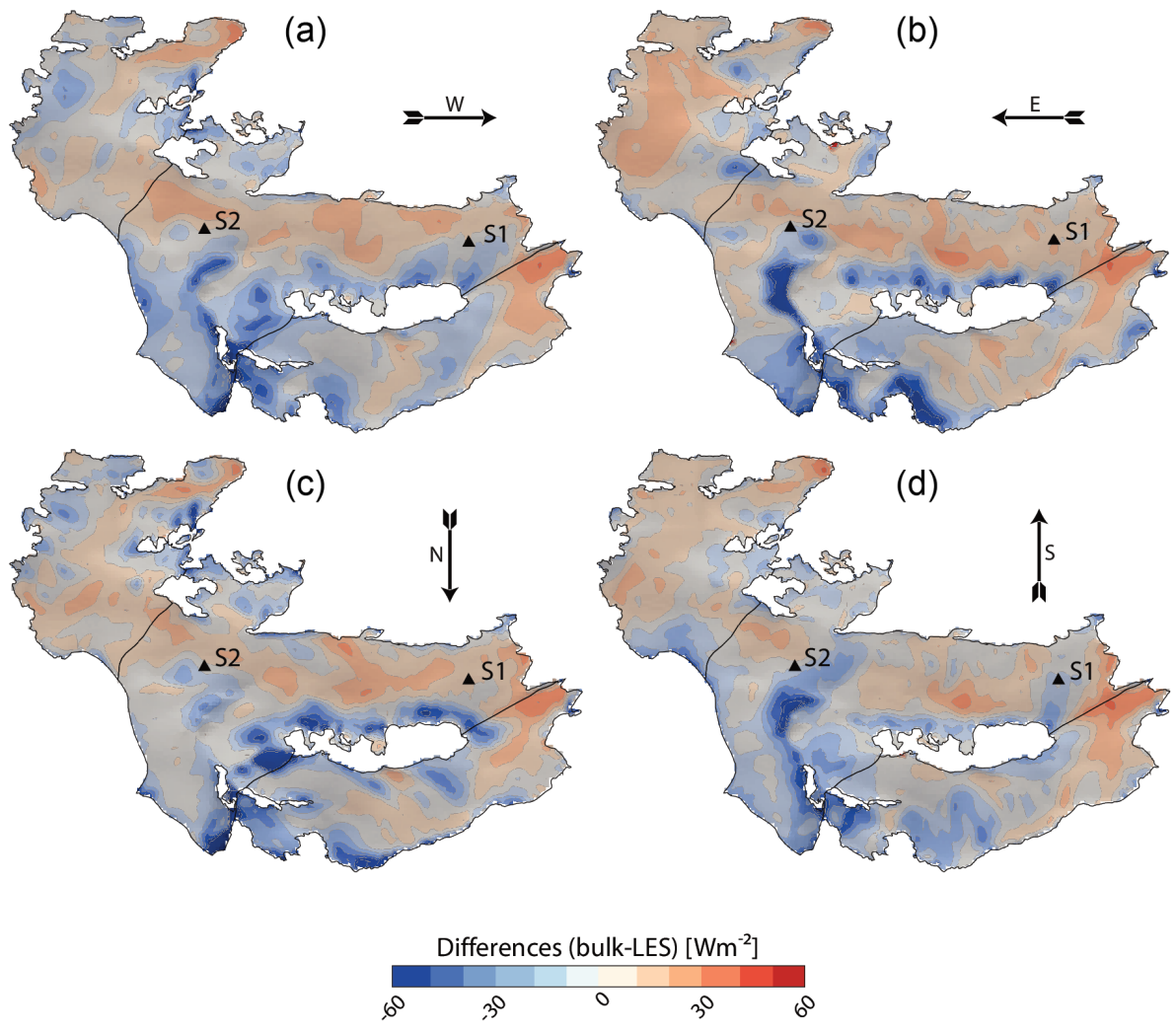

Figure 10. Differences in the mean surface sensible heat fluxes between the LES and the bulk method for different wind direction. Positive differences correspond to an overestimation of the surface heat flux by the bulk approach.

insolation on slopes due to exposure, aspect or shadow cause upslope flows to be inhomogeneous. The different onsets of the slope winds then lead to more asymmetric cross-valley circulations.

\section{Estimation of the sensible heat flux using the bulk approach}

Physically based distributed mass balance models are often applied to translate the local-scale weather conditions into net mass gain and loss at the glacier surface. The ablation process, which removes ice and snow, is controlled by the net energy balance at the ice-atmosphere interface. Direct measurements of energy balance components exist in most cases only for radiation, while surface heat and moisture fluxes are rarely measured directly on glaciers. The simplest and most widely used method to parameterize the turbulent energy exchange from available meteorological observations is the bulk approach. The approach is based on the MoninObukhov theory and assumes constant fluxes within the surface layer. This is not necessarily true in the presence of a LLJ, but the method is found to give good results when measurements are below the wind velocity maximum (Greuell and Smeets, 2001). The sensible heat flux is usually esti- mated by

$$
Q_{H}=\frac{\rho c_{p} \kappa^{2} U\left(T_{\mathrm{a}}-T_{\mathrm{s}}\right)}{\left[\ln \left(\frac{z}{z_{0}}\right)+\psi_{\mathrm{m}}\left(\frac{z}{L_{\mathrm{s}}}\right)\right]\left[\ln \left(\frac{z}{z_{0 \mathrm{~h}}}\right)+\psi_{\mathrm{h}}\left(\frac{z}{L_{\mathrm{s}}}\right)\right]},
$$

where $\rho$ is the air density $\left(\mathrm{kg} \mathrm{m}^{-3}\right), c_{p}$ the specific heat of air at constant pressure $\left(1004 \mathrm{~J} \mathrm{~kg}^{-1} \mathrm{~K}^{-1}\right), \kappa$ is the von Karman constant (0.4), $U$ is the wind velocity $\left(\mathrm{m} \mathrm{s}^{-1}\right), T_{\mathrm{a}}$ the air temperature $(\mathrm{K})$ at the height $z(\mathrm{~m})$ and $T_{\mathrm{S}}$ the surface. The parameters $z_{0}$ and $z_{0 \mathrm{~h}}(\mathrm{~m})$ are the roughness lengths for momentum and heat, respectively. The characteristic length scale $L_{\mathrm{s}}(\mathrm{m})$ is the Obukhov length and is proportional to the height of the dynamic sub-layer. The vertically integrated stability functions for momentum, $\psi_{\mathrm{m}}$, and heat, $\psi_{\mathrm{h}}$, are given as

$\psi_{\mathrm{m}}=\psi_{\mathrm{h}}=\frac{4.7 \cdot z}{L_{\mathrm{s}}}$.

\subsection{Shortcomings in the sensible heat flux estimates related to the large-scale flow direction}

It is straightforward to apply Eq. (18) to any given point on the glacier, in case all quantities are known. However, highly resolved observational data on glaciers, as required to characterize the spatial fields, are usually scarce and need to be 
extrapolated. Extrapolation algorithms in turn are based on simplified distribution assumptions and are unlikely to sufficiently reconstruct the full variability of a quantity in time and space. To identify the shortcomings in the local sensible heat flux estimates due to deficiencies in the observations (extrapolation), we consider the LES as pseudo-reality. The pseudo-reality atmosphere is not required to be an observed real world case, but it needs to be plausible in the sense that relevant processes are realistically simulated. As demonstrated in Sect. 3.1, 3.2 and 3.3, the LES provide plausible realizations of the vertical wind and temperature profiles, sensible heat fluxes and turbulent structures of the boundary layer.

To illustrate how the sensible heat flux estimates depend on the local flow conditions, we define two pseudoobservation sites at Zufallferner, with preferable great vertical differences between the sites (S1 and S2, see Fig. 10). The simulated (LES) wind velocities and temperatures at the two sites are linearly extrapolated across the glacier to obtain a temperature field (e.g., Paul and Kotlarski, 2010; Machguth et al., 2009; Huintjes et al., 2015; Weidemann et al., 2013; Jarosch et al., 2012). For comparison, we also estimate a second temperature field using a simple thermodynamic glacier wind model that accounts for air temperature variations along the flow line. The model details are given in Greuell and Böhm (1998), Ayala et al. (2015), Petersen et al. (2013) and Carturan et al. (2015). The model is fitted to the observations by optimizing the bulk transfer coefficient for heat and the location on the glacier from where air parcels are dominated by the katabatic wind. Assuming that the Obukhov length, $L_{\mathrm{S}}$, equals the observed value at $\mathrm{S} 1$, the sensible heat flux is then calculated at all grid points (Eq. 18).

Figure 10 shows the differences between the LES and the calculated sensible heat fluxes using the linearly interpolated temperature fields together with the bulk method. As $T_{\mathrm{s}}, z_{0}$ and $L_{\mathrm{S}}$ are known from the LES, the discrepancies must be the result of the insufficient characterization of the spatial $U$ and $T_{\mathrm{a}}$ fields. It is evident that the forcing fields cannot reflect the variability of the local processes which originate from the complex topography. Shortcomings are eminently striking in regions of warm air advection (see Sect. 3.3 and Fig. 9). This approach, for instance, underestimates the fluxes by up to $40 \mathrm{~W} \mathrm{~m}^{-2}$ in the peripheral zone of Zufallferner (steep slopes) and also in the vicinity of S2. Local advection processes equally explain the deficits in the higher regions of Fürkele Ferner.

In contrast, the fluxes are largely overestimated along the glacier centerlines and tongues. In these regions the welldeveloped katabatic flow prevents warm air advection from the surroundings (see Sect. 3.1). For example, this is the case at the tongues of Fürkele Ferner and Zufallferner, where glacier winds converge due to the topography. Here, the persistent winds are barely perturbed by the warm air advection from the surrounding terrain. Instead, the air continuously cools on the way down the glacier by a downward sensi- ble heat flux and is therefore potentially cooler than in other parts of the glacier. The linear temperature gradients, determined from the two locations ( $\mathrm{S} 1$ and $\mathrm{S} 2$ ), do not account for this additional cooling. Hence, the extrapolated fields are too warm and the bulk approach overestimates the sensible heat fluxes by $10-30 \mathrm{~W} \mathrm{~m}^{-2}$.

On a glacier scale, the bulk approach in concert with linearly interpolated temperature fields underestimates the average heat flux between $5.2(-16.6 \%)$ and $6.9 \mathrm{Wm}^{-2}$ $(-20.3 \%)$ for the westerly, easterly and northerly flow (see Table 2). The local differences for the southerly case, however, almost cancel each other out $\left(0.8 \mathrm{~W} \mathrm{~m}^{-2}, 2.2 \%\right)$. The thermodynamic glacier model accounts for the cooling of air parcels along the flow path due to the turbulent heat exchange and reproduces the cooler temperatures at the glacier tongue (not shown). At the lateral glacier boundaries, the model is generally cooler than the LES, so that it slightly underestimates the glacier-wide averaged sensible heat fluxes (see Table 2).

\subsection{Shortcomings in the sensible heat flux estimates due to the choice of observation sites}

The choice and number of observation sites on glaciers is always a compromise between logistic feasibility, financial expenditure and scientific issue. These factors usually restrict the monitoring activities to a few sites along the glacier centerlines. Even from a purely scientific perspective the choice of observation sites that meet all requirements is challenging.

To explore how the choice of observation sites influences the spatial variation of the sensible heat flux estimates, we define a set of pseudo-observation on Zufallferner (S1-S5; see Fig. 11 and Table 3) with distinct flow and advection patterns: (S1) located at the glacier tongue with almost pure katabatic wind (used as reference station); (S2) in the higher region, which is influenced by strong heat advection; (S3) at the lateral boundary of the glacier, which is influenced by the cross-valley circulation; (S4) close to S2 but less affected by strong heat advection; and (S5) a second station on the glacier with dominantly katabatic wind. In the following, we estimate the sensible heat flux according to Eq. (18) for each combination of S1 and S2-S5 using the linearly extrapolated temperature and mean wind velocity (the mean value of the two sites) from the westerly flow case. This approach has two major implications: (i) the temperature field is completely decoupled from the flow and therefore disregards local flow features (e.g., gap flows and bluff bodies), and (ii) the wind velocities are too low over large areas on the glacier.

Figure 11 shows the differences between the sensible heat fluxes calculated by the bulk approach and the surrogate atmospheres. Evidently, the bulk approach in concert with interpolated temperature fields underestimates the spatial sensible heat flux variability. Since the spatial patterns are similar for all cases, the shortcoming must be related to the insufficient characterization of the temperature advection process. 
Table 3. Mean glacier-wide sensible heat fluxes using the bulk approach with linearly extrapolated temperature and wind fields. The table shows extrapolation scenarios based on different pseudo-observations (S1, S2-S5). The exact location of the pseudo-observations is given in Fig. 11. Given are the mean and relative differences between the bulk estimates and LES as well as the lapse rates. Positive differences correspond to an overestimation of the fluxes by the bulk approach.

\begin{tabular}{lrrrr}
\hline & S1-S2 & S1-S3 & S1-S4 & S1-S5 \\
\hline Bulk approach $\left(\mathrm{W} \mathrm{m}^{-2}\right)$ & 42.76 & 49.66 & 28.85 & 18.77 \\
Mean difference $\left(\mathrm{W} \mathrm{m}^{-2}\right)$ & 9.82 & 16.58 & -4.04 & -14.53 \\
Mean relative difference $(\%)$ & 26.5 & 46.9 & -14.6 & -44.4 \\
Lapse rate $\left(\mathrm{Km}^{-1}\right)$ & -0.003 & 0.006 & -0.004 & -0.006 \\
\hline
\end{tabular}
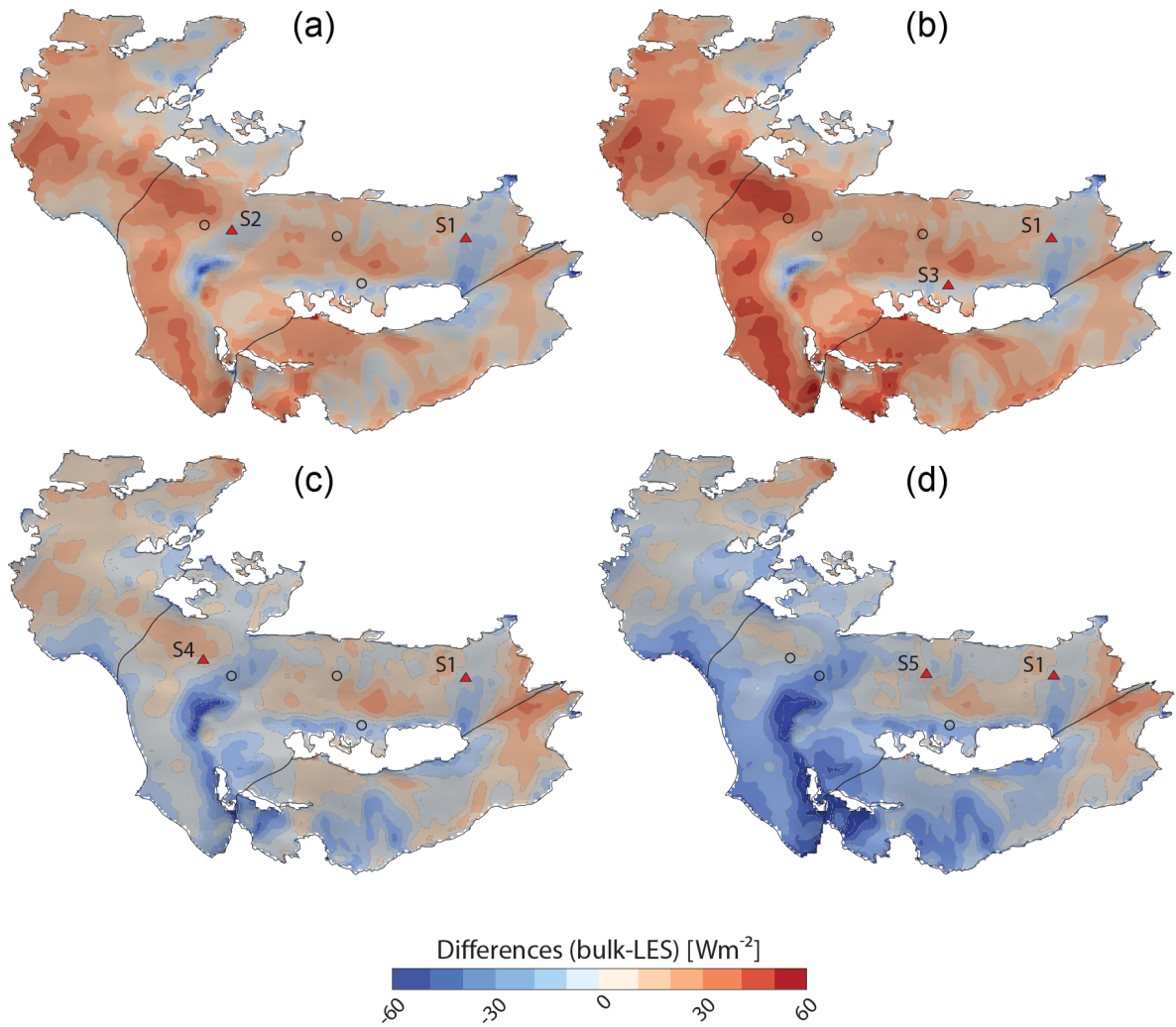

Figure 11. Differences in the surface sensible heat fluxes between the LES and the bulk method. The cases (a)-(d) indicate different extrapolation scenarios based on the pseudo-observations (S1, S2-S5). Positive differences correspond to regions where the fluxes have been overestimated by the bulk approach.

The magnitude of the differences, however, results from the derived temperature gradients, and thus the location of the second station, S2-S5 (see Table 3). In the case that stations are located in a region of strong temperature advection (e.g., case $\mathrm{S} 1-\mathrm{S} 2$ and $\mathrm{S} 1-\mathrm{S} 3$ ), the derived temperature gradient is too shallow, and the bulk approach overestimates the sensible heat fluxes in most regions of the glacier. Similarly, temperature gradients are too steep when stations are protected from warm air transport, and on average fluxes are underestimated (e.g., case S1-S4 and S1-S5). On glacier-wide average the excess/deficit in energy varies between -14.5 and 16.6 $\mathrm{W} \mathrm{m}^{-2}$ (see Table 3 ).
The results confirm that the phenomenological understanding at few locations and weather situation is not valid beyond the case and insufficient to infer on the micrometeorological conditions on mountain glaciers.

\section{Conclusions}

We have shown how complex topography influences the micrometeorological conditions on three midlatitude mountain glaciers in the Italian Ortles-Cevedale Group. The idealized LES experiments demonstrate that heat advection associated with the wind systems shapes the thermal conditions on the 
glaciers during the course of a summer day with clear sky conditions. In particular, the cross-valley circulations, and bluff body formations behind sharp ridges, transport warm air from the surroundings to the peripheral zones of the glaciers and locally increase the sensible heat fluxes by 50 $100 \mathrm{~W} \mathrm{~m}^{-2}$. Intermittent downburst events, however, entrain little heat from the free atmosphere towards the surface. The effective energy surplus is supposed to be even higher when the longwave radiation is parameterized by air temperature.

Our pseudo-reality experiments demonstrate that it is challenging to fully characterize the micrometeorological conditions over glacier surfaces from a limited number of observations. Linearly extrapolated forcing fields fail to reflect the temperature variability that originates from insufficient characterization of advection. The shortcomings in the forcing fields have direct consequences on estimated sensible heat fluxes (e.g., by the bulk approach). Local differences in the sensible heat fluxes of up to $60 \mathrm{~W} \mathrm{~m}^{-2}$ are strong enough to significantly affect the ablation rate estimates, as well as the derived climate sensitivities of mountain glaciers.

The choice of observations sites, and thus the derived temperature gradients, determines the magnitude of the local sensible heat flux errors. Calculated temperature lapse rates are shallower $\left(<-0.003 \mathrm{Km}^{-1}\right)$ than the environmental lapse rate $\left(-0.0065 \mathrm{~K} \mathrm{~m}^{-1}\right)$ or even change sign $\left(+0.006 \mathrm{Km}^{-1}\right.$, see Table 3$)$ when the higher stations are influenced by warm air advection. Consequently, the overestimated air temperatures produce higher downward-directed sensible heat fluxes for most parts of the glaciers. In case stations are protected from warm air transport or located in well developed katabatic flows, calculated temperature gradients are generally steeper $\left(>-0.005 \mathrm{Km}^{-1}\right)$ than the environmental lapse rate. The shallow lapse rates result in very low sensible heat flux estimates in the peripheral and higher zones of the glaciers, where heat advection is an important process. Generally, the sensitivity of the calculated lapse rates to the choice of the observation sites is related to the steep gradients between the advected warm air masses and the ambient cold air masses on the glacier. Shifting stations by even small distances $(\leq 200 \mathrm{~m})$ can potentially lead to remarkable differences in the calculated lapse rates of $\pm 0.005 \mathrm{Km}^{-1}$.

As a glacier-wide average, the choice of observation sites causes differences of about $\pm 16 \mathrm{~W} \mathrm{~m}^{-2}(\sim 20 \%$ of the actual LES value). The estimated errors are considered conservative given the weak geostrophic forcing and low surface heating rate. However, the error quantification is only valid for the specific experimental design, and the infinite topographic possibilities and variety of site combinations make it impossible to draw a general conclusion about the best sites on a glacier.

We can conclude that a profound knowledge of the heat advection process is needed when small-scale variations of surface energy balance are required for distributed mass balance studies. Current thermodynamic and statistical center- line models describe temperature variations along the flow line of glaciers, but they do not resolve the cross-glacier variability (e.g., Greuell and Böhm, 1998; Shea and Moore, 2010; Carturan et al., 2015; Ayala et al., 2015; Petersen et al., 2013). In order to account for the lateral variations, temperature and wind fields need to be coupled. We suggest that future efforts should consider more representative wind fields (e.g., simulated by mass-consistent models) in concert with simple centerline models.

\section{Data availability}

The LES data are available upon request from Tobias Sauter. The open-source CFD software OpenFOAM can be downloaded from http://www.openfoam.com. The Schumann surface shear stress model was developed by Churchfield et al. (2014) from the National Renewable Energy Laboratory (NREL, https://nwtc.nrel.gov/SOWFA). This code can be downloaded from the online repository https://github.com/ NREL/SOWFA, hosted by GitHub (https://github.com).

Acknowledgements. We gratefully acknowledge financial support by the Deutsche Forschungsgemeinschaft (DFG), no. SA 2339/4-1. This work was also supported and partly financed by the Autonome Provinz Bozen - Südtirol, Abteilung Bildungsförderung, Universität und Forschung. We thank both reviewers for their detailed comments and constructive criticism of the original manuscript.

Edited by: V. Radic

Reviewed by: two anonymous referees

\section{References}

Anderson, R. and Meneveau, C.: Effects of the similarity model in finite-difference LES of isotropic turbulence using a Lagrangian dynamic mixed model, Flow Turbul. Combust., 62, 201-225, 1999.

Arnold, N., Willis, I., Sharp, M., Richards, K., and Lawson, W.: A distributed surface energy-balance model for a small valley glacier. I. Development and testing for Haut Glacier d Arolla, Valais, Switzerland, J. Glaciol., 42, 77-89, doi:10.3198/1996JoG42-140-77-89, 1996.

Ayala, A., Pellicciotti, F., and Shea, J.: Modeling $2 \mathrm{~m}$ air temperatures over mountain glaciers: Exploring the influence of katabatic cooling and external warming, J. Geophys. Res.-Atmos., 120, 3139-3157, 2015.

Basu, S., Holtslag, A. A., Van De Wiel, B. J., Moene, A. F., and Steeneveld, G.-J.: An inconvenient "truth" about using sensible heat flux as a surface boundary condition in models under stably stratified regimes, Acta Geophys., 56, 88-99, 2008.

Beare, R. J., Macvean, M. K., Holtslag, A. A., Cuxart, J., Esau, I., Golaz, J.-C., Jimenez, M. A., Khairoutdinov, M., Kosovic, B., Lewellen, D., Lund, T. S., Lundquist, J. K., Mccabe, A., Moene, A. F., Noh, Y., Raasch, S., and Sullivan, P.: An intercomparison 
of large-eddy simulations of the stable boundary layer, Bound.Lay. Meteorol., 118, 247-272, 2006.

Bou-Zeid, E., Meneveau, C., and Parlange, M.: A scaledependent Lagrangian dynamic model for large eddy simulation of complex turbulent flows, Phys. Fluids, 17, 025105, doi:10.1063/1.1839152, 2005.

Braithwaite, R.: Aerodynamic stability and turbulent sensible-heat flux over a melting ice surface, the Greenland ice sheet, J. Glaciol., 41, 562-571, 1995.

Brock, B., Willis, I., Sharp, M., and Arnold, N.: Modelling seasonal and spatial variations in the surface energy balance of Haut Glacier d'Arolla, Switzerland, Ann. Glaciol., 31, 53-62, 2000.

Brock, B. W., Willis, I. C., and Sharp, M. J.: Measurement and parameterization of aerodynamic roughness length variations at Haut Glacier d'Arolla, Switzerland, J. Glaciol., 52, 281-297, 2006.

Carturan, L., Cazorzi, F., De Blasi, F., and Dalla Fontana, G.: Air temperature variability over three glaciers in the Ortles-Cevedale (Italian Alps): effects of glacier fragmentation, comparison of calculation methods, and impacts on mass balance modeling, The Cryosphere, 9, 1129-1146, doi:10.5194/tc-9-1129-2015, 2015.

Churchfield, M. J., Lee, S., and Moriarty, P. J.: Adding complex terrain and stable atmospheric condition capability to the OpenFOAM-based flow solver of the simulator for on/offshore wind farm applications (SOWFA), in: ITM Web of Conferences, vol. 2, p. 02001, EDP Sciences, 2014.

Cullen, N., Steffen, K., and Blanken, P.: Nonstationarity of turbulent heat fluxes at Summit, Greenland, Bound.-Lay. Meteorol., 122, 439-455, 2007.

Cullen, N. J. and Conway, J. P.: A 22 month record of surface meteorology and energy balance from the ablation zone of Brewster Glacier, New Zealand, J. Glaciol., 61, 931-946, 2015.

Dadic, R., Mott, R., Lehning, M., Carenzo, M., Anderson, B., and Mackintosh, A.: Sensitivity of turbulent fluxes to wind speed over snow surfaces in different climatic settings, Adv. Water Resour., 55, 178-189, 2013.

Dee, D. P., Uppala, S. M., Simmons, A. J., Berrisford, P., Poli, P., Kobayashi, S., Andrae, U., Balmaseda, M. A., Balsamo, G., Bauer, P., Bechtold, P., Beljaars, A. C. M., van de Berg, L., Bidlot, J., Bormann, N., Delsol, C., Dragani, R., Fuentes, M., Geer, A. J., Haimberger, L., Healy, S. B., Hersbach, H., Hólm, E. V., Isaksen, L., Kållberg, P., Köhler, M., Matricardi, M., McNally, A. P., Monge-Sanz, B. M., Morcrette, J.-J., Park, B.-K., Peubey, C., de Rosnay, P., Tavolato, C., Thépaut, J.-N., and Vitart, F.: The ERA-Interim reanalysis: configuration and performance of the data assimilation system, Q. J. Roy. Meteor. Soc., 137, 553-597, doi:10.1002/qj.828, 2011.

Frías, M. D., Zorita, E., Fernández, J., and Rodríguez-Puebla, C.: Testing statistical downscaling methods in simulated climates, Geophys. Res. Lett., 33, L19807, doi:10.1029/2006GL027453, 2006.

Galos, S., Klug, C., Prinz, R., Rieg, L., Sailer, R., Dinale, R., and Kaser, G.: Recent glacier changes and related contribution potential to river discharge in the Vinschgau/Val Venosta, Italian Alps, Geogr. Fis. Din. Quat., 38, 143-154, doi:10.4461/GFDQ.2015.38.13, 2015.

Gardner, A. S., Moholdt, G., Cogley, J. G., Wouters, B., Arendt, A. A., Wahr, J., Berthier, E., Hock, R., Pfeffer, W. T., Kaser, G., Ligtenberg, S. R. M., Bolch, T., Sharp, M. J., Hagen, J. O., van den Broeke, M. R., and Paul, F.: A reconciled estimate of glacier contributions to sea level rise: 2003 to 2009, Science, 340, 852-857, doi:10.1126/science.1234532, 2013.

Giessen, R., Van den Broeke, M., Oerlemans, J., and Andreassen, L.: Surface energy balance in the ablation zone of Midtdalsbreen, a glacier in southern Norway: Interannual variability and the effect of clouds, J. Geophys. Res., 113, 1-17, 2008.

Gillett, S. and Cullen, N. J.: Atmospheric controls on summer ablation over Brewster Glacier, New Zealand, Int. J. Climatol., 31, 2033-2048, 2011.

Greuell, W. and Böhm, R.: $2 \mathrm{~m}$ temperatures along melting midlatitude glaciers, and implications for the sensitivity of the mass balance to variations in temperature, J. Glaciol., 44, 9-20, 1998.

Greuell, W. and Smeets, P.: Variations with elevation in the surface energy balance on the Pasterze (Austria), J. Geophys. Res., 106, 31717-31727, 2001.

Gurgiser, W., Molg, T., Nicholson, L., and Kaser, G.: Mass-balance model parameter transferability on a tropical glacier, J. Glaciol. 59, 845-858, doi:10.3189/2013JoG12J226, 2013.

Hannah, D. M., Gurnell, A. M., and Mcgregor, G. R.: Spatiotemporal variation in microclimate, the surface energy balance and ablation over a cirque glacier, Int. J. Climatol., 20, 733-758, 2000.

Helgason, W. and Pomeroy, J.: Characteristics of the near-surface boundary layer within a mountain valley during winter, J. Appl. Meteorol. Clim., 51, 583-597, 2012.

Hock, R.: Glacier melt: a review of processes and their modelling, Prog. Phys. Geog., 29, 362-391, 2005.

Hock, R. and Holmgren, B.: A distributed surface energybalance model for complex topography and its application to Storglaciaären, Sweden, J. Glaciol., 51, 25-36, doi:10.3189/172756505781829566, 2005.

Högström, U., Hunt, J., and Smedman, A.: Theory and measurements for turbulence spectra and variances in the atmospheric neutral surface layer, Bound.-Lay. Meteorol., 103, 101-124, 2002.

Hoinkes, H.: Beiträge zur Kenntnis des Gletscherwindes, Archiv für Meteorologie, Geophysik und Bioklimatologie, Serie B, 6, 36-53, 1954

Huintjes, E., Sauter, T., Schröter, B., Maussion, F., Yang, W., Kropácek, J., Buchroithner, M., Scherer, D., Kang, S., and Schneider, C.: Evaluation of a coupled snow and energy balance model for Zhadang glacier, Tibetan Plateau, using glaciological measurements and time-lapse photography, Arct. Antarct. Alp. Res., 47, 573-590, 2015.

Immerzeel, W., Petersen, L., Ragettli, S., and Pellicciotti, F.: The importance of observed gradients of air temperature and precipitation for modeling runoff from a glacierized watershed in the Nepalese Himalayas, Water Resour. Res., 50, 2212-2226, 2014.

Jarosch, A. H., Anslow, F. S., and Clarke, G. K.: High-resolution precipitation and temperature downscaling for glacier models, Clim. Dynam., 38, 391-409, 2012.

Klok, E. and Oerlemans, J.: Model study of the spatial distribution of the energy and mass balance of Morteratschgletscher, Switzerland, J. Glaciol., 48, 505-518, 2002.

Kosovic, B. and Curry, J. A.: A large eddy simulation study of a quasi-steady, stably stratified atmospheric boundary layer, J. Atmos. Sci., 57, 1052-1068, 2000. 
Kuhn, M.: Die Höhe des Geschwindigkeitsmaximums im Gletscherwind als Parameter des Wärmehaushalts, Arbeiten aus der Zentralanstalt für Meteorologie und Geodynamik, Wien, 31, 1-69, 1978.

Litt, M., Sicart, J.-E., Helgason, W. D., and Wagnon, P.: Turbulence characteristics in the atmospheric surface layer for different wind regimes over the tropical Zongo glacier, Bound.-Lay. Meteorol., 154, 471-495, 2015.

MacDougall, A. H. and Flowers, G. E.: Spatial and temporal transferability of a distributed energy-balance glacier melt model, J. Climate, 24, 1480-1498, doi:10.1175/2010JCLI3821.1, 2011.

Machguth, H., Paul, F., Hoelzle, M., and Haeberli, W.: Distributed glacier mass-balance modelling as an important component of modern multi-level glacier monitoring, Ann. Glaciol., 43, 335343, 2006

Machguth, H., Paul, F., Kotlarski, S., and Hoelzle, M.: Calculating distributed glacier mass balance for the Swiss Alps from regional climate model output: A methodical description and interpretation of the results, J. Geophys. Res., 114, D19106, doi:10.1029/2009JD011775, 2009.

Mahrt, L.: Variability and maintenance of turbulence in the very stable boundary layer, Bound.-Lay. Meteorol., 135, 1-18, 2010.

Maraun, D.: Nonstationarities of regional climate model biases in European seasonal mean temperature and precipitation sums, Geophys. Res. Lett., 39, L06706, doi:10.1029/2012GL051210, 2012.

Meneveau, C., Lund, T. S., and Cabot, W. H.: A Lagrangian dynamic subgrid-scale model of turbulence, J. Fluid Mech., 319, 353-385, 1996.

Mölg, T. and Hardy, D. R.: Ablation and associated energy balance of a horizontal glacier surface on Kilimanjaro, J. Geophys. Res., 109, D16104, doi:10.1029/2003JD004338, 2004.

Mölg, T., Cullen, N. J., Hardy, D. R., Winkler, M., and Kaser, G.: Quantifying climate change in the tropical midtroposphere over East Africa from glacier shrinkage on Kilimanjaro, J. Climate, 22, 4162-4181, doi:10.1175/2009JCLI2954.1, 2009.

Moore, R. and Owens, I.: Controls on advective snowmelt in a maritime alpine basin, J. Clim Appl. Meteorol., 23, 135-142, 1984.

Munro, D. and Davies, J.: On fitting the log-linear model to wind speed and temperature profiles over a melting glacier, Bound.Lay. Meteorol., 15, 423-437, 1978.

Munro, D. and Scott, J.: Surface roughness and bulk heat transfer on a glacier: comparison with eddy correlation, J. Glaciol., 35, 343-348, 1989.

Nicholson, L. I., Prinz, R., Mölg, T., and Kaser, G.: Micrometeorological conditions and surface mass and energy fluxes on Lewis Glacier, Mt Kenya, in relation to other tropical glaciers, The Cryosphere, 7, 1205-1225, doi:10.5194/tc-7-1205-2013, 2013.

Obleitner, F. and Lehning, M.: Measurement and simulation of snow and superimposed ice at the Kongsvegen glacier, Svalbard (Spitzbergen), J. Geophys. Res., 109, D04106, doi:10.1029/2003JD003945, 2004.

Oerlemans, J. and Grisogono, B.: Glacier winds and parameterisation of the related surface heat fluxes, Tellus A, 54, 440-452, 2002.

Oerlemans, J. and Klok, E.: Energy balance of a glacier surface: analysis of automatic weather station data from the Morteratschgletscher, Switzerland, Arct. Antarct. Alp. Res., 34, 477485, 2002.
Paul, F. and Kotlarski, S.: Forcing a distributed glacier mass balance model with the regional climate model REMO. Part II: downscaling strategy and results for two Swiss glaciers, J. Climate, 23, 1607-1620, 2010

Petersen, L., Pellicciotti, F., Juszak, I., Carenzo, M., and Brock, B.: Suitability of a constant air temperature lapse rate over an Alpine glacier: testing the Greuell and Böhm model as an alternative, Ann. Glaciol., 54, 120-130, 2013.

Pope, S. B.: Turbulent flows, Cambridge University Press, 558-639, 2000.

Poulos, G., Bosser, J., McKee, T., and Pielke, R.: The interaction of katabatic flow and mountain waves, J. Atmos. Sci., 64, 1857 1879, 2007.

Prinz, R., Nicholson, L. I., Mölg, T., Gurgiser, W., and Kaser, G.: Climatic controls and climate proxy potential of Lewis Glacier, Mt. Kenya, The Cryosphere, 10, 133-148, doi:10.5194/tc-10133-2016, 2016.

Reijmer, C. and Hock, R.: A distributed energy balance model including a multi-layer sub-surface snow model, J. Glaciol., 54 61-72, 2008

Roesch, A. and Schmidbauer, H.: WaveletComp: Computational Wavelet Analysis, $\mathrm{r}$ package version 1.0, available at: http://www.hs-stat.com/projects/WaveletComp/WaveletComp_ guided_tour.pdf, last access: 15 February 2016, 2014.

Sarghini, F., Piomelli, U., and Balaras, E.: Scale-similar models for large-eddy simulations, Phys. Fluids, 11, 1596-1607, 1999.

Schumann, U.: Subgrid scale model for finite difference simulations of turbulent flows in plane channels and annuli, J. Comput. Phys., 18, 376-404, 1975.

Shaw, T. E., Brock, B. W., Fyffe, C. L., Pellicciotti, F., Rutter, N., and Diotri, F.: Air temperature distribution and energy-balance modelling of a debris-covered glacier, J. Glaciol., 62, 185-198, 2016.

Shea, J. and Moore, R.: Prediction of spatially distributed regional-scale fields of air temperature and vapor pressure over mountain glaciers, J. Geophys. Res., 115, D23107, doi:10.1029/2010JD014351, 2010.

Sicart, J., Litt, M., Helgason, W., Ben Tahar, V., and Chaperon, T.: A study of the atmospheric boundary layer and roughness length of the high altitude tropical Zongo glacier, Bolivia, J. Geophys. Res., 119, 3793-3808, 2014.

Smeets, C., Duynkerke, P., and Vugts, H.: Turbulence characteristics of the stable boundary layer over a mid-latitude glacier. Part I: A combination of katabatic and large-scale forcing, Bound.Lay. Meteorol., 87, 117-145, 1998.

Smeets, C., Duynkerke, P., and Vugts, H.: Turbulence characteristics of the stable boundary layer over a mid-latitude glacier. Part II: Pure katabatic forcing conditions, Bound.-Lay. Meteorol., 97, 73-107, 2000.

Söderberg, S. and Parmhed, O.: Numerical Modelling of Katabatic Flow Over a Melting Outflow Glacier, Bound.-Lay. Meteorol., 120, 509-534, doi:10.1007/s10546-006-9059-3, 2006.

Stoll, R. and Porté-Agel, F.: Dynamic subgrid-scale models for momentum and scalar fluxes in large-eddy simulations of neutrally stratified atmospheric boundary layers over heterogeneous terrain, Water Resour. Res., 42, W01409, doi:10.1029/2005WR003989, 2006.

Strasser, U., Corripio, J., Pellicciotti, F., Burlando, P., Brock, B., and Funk, M.: Spatial and temporal variability of meteorological 
variables at Haut Glacier d'Arolla (Switzerland) during the ablation season 2001: Measurements and simulations, J. Geophys. Res., 109, D03103, doi:10.1029/2003JD003973, 2004.

Stull, R. B.: An introduction to boundary layer meteorology, Springer Science \& Business Media, 13, 347-404, 2012.

Torrence, C. and Compo, G.: A practical guide to wavelet analysis, B. Am. Meteor. Soc., 79, 61-78, 1998.

van den Broeke, M.: Structure and diurnal variation of the atmospheric boundary layer over a mid-latitude glacier in summer, Bound.-Lay. Meteorol., 83, 183-205, doi:10.1023/A:1000268825998, 1997.

van den Broeke, M. R.: Momentum, heat, and moisture budgets of the katabatic wind layer over a midlatitude glacier in summer, J. Appl. Meteorol., 36, 763-774, 1997.

Vrac, M., Stein, M., Hayhoe, K., and Liang, X.-Z.: A general method for validating statistical downscaling methods under future climate change, Geophys. Res. Lett., 34, doi:10.1029/2007GL030295, 2007.
Wagnon, P., Ribstein, P., Francou, B., and Pouyaud, B.: Annual cycle of energy balance of Zongo glacier, Cordillera Real, Bolivia, J. Geophys. Res., 104, 3907-3923, 1999.

Wan, F., Porté-Agel, F., and Stoll, R.: Evaluation of dynamic subgrid-scale models in large-eddy simulations of neutral turbulent flow over a two-dimensional sinusoidal hill, Atmos. Environ., 41, 2719-2728, 2007.

Weidemann, S., Sauter, T., Schneider, L., and Schneider, C.: Impact of two conceptual precipitation downscaling schemes on massbalance modeling of Gran Campo Nevado ice cap, Patagonia, J. Glaciol., 59, 1106-1116, 2013.

Zemp, M., Thibert, E., Huss, M., Stumm, D., Rolstad Denby, C., Nuth, C., Nussbaumer, S. U., Moholdt, G., Mercer, A., Mayer, C., Joerg, P. C., Jansson, P., Hynek, B., Fischer, A., Escher-Vetter, H., Elvehøy, H., and Andreassen, L. M.: Reanalysing glacier mass balance measurement series, The Cryosphere, 7, 12271245, doi:10.5194/tc-7-1227-2013, 2013. 